\title{
Pathway deregulation and expression QTLs in response to Actinobacillus pleuropneumoniae infection in swine
}

\author{
Gerald Reiner • Felix Dreher • Mario Drungowski • Doris Hoeltig • \\ Natalie Bertsch • Martin Selke • Hermann Willems • Gerald Friedrich Gerlach • \\ Inga Probst • Burkhardt Tuemmler · Karl-Heinz Waldmann · Ralf Herwig
}

Received: 3 April 2014/ Accepted: 10 July 2014/Published online: 14 August 2014

(C) Springer Science+Business Media New York 2014

\begin{abstract}
Actinobacillus (A.) pleuropneumoniae is among the most important pathogens in pig. The agent causes severe economic losses due to decreased performance, the occurrence of acute or chronic pleuropneumonia, and an increase in death incidence. Since therapeutics cannot be used in a sustainable manner, and vaccination is not always available, new prophylactic measures are urgently needed. Recent research has provided evidence for a genetic predisposition in susceptibility to $A$. pleuropneumoniae in a Hampshire $\times$ German Landrace F2 family with 170 animals. The aim of the present study is to characterize the expression response in this family in order to unravel resistance and susceptibility mechanisms and to prioritize candidate genes for future fine mapping approaches. F2 pigs differed distinctly in clinical, pathological, and microbiological parameters after challenge with
\end{abstract}

Electronic supplementary material The online version of this article (doi:10.1007/s00335-014-9536-9) contains supplementary material, which is available to authorized users.

G. Reiner $(\bowtie) \cdot$ N. Bertsch $\cdot$ H. Willems

Department of Veterinary Clinical Sciences, Justus-LiebigUniversity, Frankfurter Strasse 112, 35392 Giessen, Germany

e-mail: gerald.reiner@vetmed.uni-giessen.de

F. Dreher

Alacris Theranostics GmbH, Fabeckstr. 60-62, 14195 Berlin, Germany

M. Drungowski

ATLAS Biolabs GmbH, Friedrichstraße 147, 10117 Berlin,

Germany

D. Hoeltig $\cdot$ K.-H. Waldmann

Clinic of Swine and Small Ruminants, Forensic Medicine and Ambulatory Service, University of Veterinary Medicine,

Bischofsholer Damm 15, 30173 Hannover, Germany
A. pleuropneumoniae. We monitored genome-wide gene expression from the 50 most and 50 least susceptible F2 pigs and identified 171 genes differentially expressed between these extreme phenotypes. We combined expression QTL analyses with network analyses and functional characterization using gene set enrichment analysis and identified a functional hotspot on SSC13, including 55 eQTL. The integration of the different results provides a resource for candidate prioritization for fine mapping strategies, such as TF, TFRC, RUNX1, TCN1, HP, CD14, among others.

\section{Introduction}

Actinobacillus (A.) pleuropneumoniae is the causative agent of porcine pleuropneumonia, characterized by a hemorrhagic and necrotizing pneumonia and fibrinous pleuritis (Haesebrouck et al. 1997). Peracute deaths, acute

M. Selke

Department of Infectious Diseases, Institute for Microbiology, University of Veterinary Medicine Hannover Foundation, Bischofsholer Damm 15, 30173 Hannover, Germany

G. F. Gerlach

Innovative Veterinary Diagnostics LTD (IVD), Heisterbergallee 12, 30453 Hannover, Germany

I. Probst · B. Tuemmler

Department of Pediatrics, Hannover Medical School (MHH), Carl-Neuberg-Strasse 1, 30625 Hannover, Germany

\section{R. Herwig}

Department of Vertebrate Genomics, Max Planck Institute for Molecular Genetics Berlin, Ihnestr. 73, 14195 Berlin, Germany 
disease with severe clinical and pathologic-anatomical outcomes, chronic pleuritis in slaughter pigs, and reduced fattening performance (Gottschalk and Taylor, 2006) are cause of extensive losses in pig production worldwide (Noyes et al. 1990).

Strategies to combat porcine pleuropneumonia include age-segregated rearing (Cleveland-Nielsen et al. 2002), vaccination, and administration of antibiotics. However, efficacy of vaccination is often hampered by limited crossserovar protection (Higgins et al. 1985; Fenwick and Henry, 1994).

In contrast, subunit vaccines convey better cross-protection (Haesebrouck et al. 1997) as has been described for a commercially available subunit vaccine containing Apx toxins and an outer membrane protein (Tumamao et al. 2004; Shao et al. 2010). However, despite vaccination, pigs were not protected against the disease. Therefore, other disease preventing measures still remain essential in controlling A. pleuropneumoniae infections (Jirawattanapong et al. 2008; Sjölund and Wallgren 2010), one of which is the treatment with antibiotics. However, abundant administration of drugs results in a growing source of antibiotic resistance (White et al. 2002, Gutiérrez-Martín et al. 2006; Zutic et al. 2008).

This aspect does not agree with the increasing demands of consumers for pork from antibiotic residue-free animals (Van Oirschot 1994). With regard to swine health and welfare, reduction of pain, suffering and damage in farmed pigs is a further serious issue that needs to be addressed (Reiner 2009).

One promising approach for the improvement of health in livestock is the selection of resistant or tolerant animals. Many examples of genetically based variation in resistance/susceptibility of food animals to various viral and bacterial agents and parasites have been gathered during the last 15 years (Reiner 2009; Bishop et al. 2010).

Recent data provided clear indications for a significant genetic difference in susceptibility to an A. pleuropneumoniae infection in challenged German breeding lines (Hoeltig et al. 2009). The porcine transferrin gene (TF; Danilowicz et al. 2009), glycoproteins (Kahlisch et al. 2009), and immune markers (Benga et al. 2009) have been regarded as potential corresponding biomarkers.

Based on the same breeding lines described by Hoeltig et al. (2009), a Hampshire x German Landrace F2 family has been set up, and QTL for clinical, pathological, and microbiological traits have been mapped (Reiner et al. 2014). Additionally, QTL for dorso-caudal chronic pleuritis, representing the chronical form of A. pleuropneumoniae were mapped by Gregersen et al. (2010). Both studies showed corresponding effects on chromosomes 2, 12, 13, and 18 linked with the clinical, pathological, and microbiological outcome of the disease.
These data provide evidence for the existence of genetic differences in resistance/susceptibility to A. pleuropneumoniae infection in swine. However, confidence intervals locating the QTL positions are generally wide. As a consequence too many positional candidate genes are to be considered for further studies.

To constrain the number of putative candidate genes, genome-wide gene expression profiling can be applied. Although causative genes do not necessarily need to be differentially expressed, and differentially expressed genes do not necessarily have to carry the quantitative trait nucleotide (QTN), differential transcriptome profiling can be used to detect relevant metabolic and gene regulatory networks and regulators.

Subsequently, gene expression phenotypes can be used to identify associations between the expression of a specific gene and the genotypes at different chromosomal locations by expression QTL (eQTL) analyses. In many clinical QTL screens (Wu et al. 2008), direct associations between the eQTL and the location of the affected gene (cis-eQTL) have been used to prioritize candidate genes. Identifying candidate genes if the eQTL and the location of the gene do not overlap (trans-eQTL) is much more challenging. In this case, the expression of multiple genes is associated with a single, common genetic regulatory locus (e.g., Yvert et al. 2003; Wessel et al. 2007; Wu et al. 2008).

Based on well-characterized F2 animals of a Hampshire/ Landrace family with 170 animals (Hoeltig et al. 2009; Reiner et al. 2014), the aim of the present study was to identify candidate genes for the resistance/susceptibility to A. pleuropneumoniae infection. We performed genomewide gene expression analysis with 100 F2 animals with most extreme clinical phenotypes and evaluated these data with an integrated bioinformatics approach consisting of eQTL analysis, network analysis, and measures for functional characterization. Our results present a resource of potential candidate genes as resistance markers for $A$. pleuropneumoniae infection in the swine.

\section{Materials and methods}

Animal breeding

Pigs used in this study emerged from a three generation family. A Hampshire boar was mated to 2 Landrace sows to produce $21 \mathrm{~F} 1$ animals, from which $2 \mathrm{~F} 1$ boars and $9 \mathrm{~F} 1$ sows were crossed avoiding full-sib matings. F1 animals were born at a German breeding company and then transferred to the Clinic for Small Ruminants and Swine, University of Veterinary Medicine, Foundation, Hannover, Germany. Here, 170 F2 pigs from 17 litters were born, raised, and studied. Before entering the challenge study, all 
pigs were tested for the absence of A. pleuropneumoniaespecific antibodies (by Apx IIA and Apx IVA ELISA, Leiner et al. 1999; Dreyfuß et al. 2004), Mycoplasma hyopneumoniae and the porcine reproductive and respiratory virus (PRRSV) (both HerdChek, IDEXX Laboratories, Westbrook, Maine, USA) by antibody ELISA and Influenza A by hemagglutination inhibition test (Hoeltig et al. 2009). All F2 pigs were clinically healthy before entering the challenge study.

The piglets were weaned at the age of 4 weeks, fed with standardized diet, and housed under standardized containment level 2 conditions with exclusive access only through a gated hygiene system.

All animals were cared for in accordance with the principles outlined in the European Convention for the Protection of Vertebrate Animals (Approval number: 33.942502-04-05/919).

Infection and clinical examination

Actinobacillus pleuropneumoniae serotype 7 (Jacobsen et al. 1996; Maas et al. 2006) was obtained from the Institute for Microbiology, University of Veterinary Medicine, Foundation, Hannover, Germany. Infection and clinical examination were established and improved in a recent project (Hoeltig et al. 2009). In short, pigs were challenged at an age of 7 weeks with a well-introduced $A$. pleuropneumoniae-containing aerosol (Baltes et al. 2001, 2003a, b; Tonpitak et al. 2002; Jacobsen et al. 2005; Hoeltig et al. 2009). The clinical status was monitored from the day of infection (day 1) to day 7 post infection (p.i.) and consisted of an evaluation of the general appearance of the pigs, a detailed examination of the respiratory tracts and the measurement of oxygen saturation by pulsoxymetry (for details, see Hoeltig et al. 2009). Additionally, ultrasonographic and radiographic examination was applied to evaluate the lung status (for further details see Hoeltig et al. 2009). Deaths of pigs between infection and necropsy were recorded.

\section{Pathological examination}

On day 7 p.i. all pigs were euthanized followed by an exact pathological examination. From all lungs, lesions were scored using the lung lesion score (LLS) proposed by Hannan et al. (1982). In brief, areas of non-physiological consistence were recorded in a schematic porcine lung map. All seven lobes were divided into five triangles. Damaged triangles were counted to determine the lobés value, where 5 was the maximum score, contributing to LLS. The values of all 7 lobes were added and resulted in the LLS with a maximum of 35. Blood, liver, and spleen samples were taken for DNA preparation
Findings from clinical, radiographic, and ultrasonographic examinations and the LLS were combined in the respiratory health score (RHS), ranging from 0 to 100 . The complex formula for RHS calculation is provided in detail by Hoeltig et al. (2009). Based on the RHS, two groups of pigs with the 50 highest and lowest scores, respectively, were formed.

\section{Bacteriological examination}

Lung tissue was taken from precisely defined (first two centimeters of the tip of each lunge lobe) positions on each of the 7 lobes and cultured on modified Columbia agar (Jacobsen and Nielsen 1995), allowing a quantitative cultural score (RIS; Re-Isolation Score) with values from 0 to 27.

Statistical analysis of phenotypic data

Phenotypic data were analyzed using IBM-SPSS, Release 19.0.0 (IBM, Herrenberg, Germany). Residues of the data were approximately normally distributed. Effects of QTLlinked markers on phenotypic traits were tested by multiple regression analysis; differences in mean values were calculated by analysis of variance (ANOVA).

\section{Markers and linkage map}

Genomic DNA were extracted from blood, liver, or spleen tissue of experimental pigs using a commercial DNA-isolation kit (Analytic Jena, Germany), which proved its qualification for DNA isolation in former studies. DNA quality and quantity was measured with an Ultrospec 1100 pro photometer (GE Healthcare Europe GmbH, Freiburg, Germany).

Informative marker loci were selected to cover all autosomes at average intervals of $15 \mathrm{cM}$. From 491 microsatellite markers selected from public sources (www. ncbi.nlm.nih.gov; www.usda.gov), 170 markers fulfilled these criteria and were used to genotype the F2 families. The comprehensive map was built using CRI-MAP (Green et al. 1990).

\section{Genome-wide expression experiments}

Lung tissues for genome-wide expression experiments were sampled from healthy sections of the lungs in all pigs. The status of the region used for sampling was controlled on the basis of pathological anatomy. Healthy and diseased regions have been found well demarked from each other.

The transcriptome was measured with a $24 \mathrm{k}$ Transcriptome Chip ('Porcine Genome Array', Affymetrix, 
USA). RNA was isolated (RNeasy Mini-Kit ${ }^{\circledR}$, Qiagene $\mathrm{GmbH}$, Hilden, Germany) from lung samples of 100 animals with the most extreme clinical phenotypes (50 most and 50 least resistant pigs). Microarray data were processed with $\mathrm{R}$ and the Bioconductor package "affy". Raw expression values were normalized using the GCRMA method. To identify differentially expressed genes between the two groups of animals, we applied Welch's unpaired $t$ test. Genes were identified as significantly differentially expressed if (i) the gene was either expressed in the resistant or the susceptible group of animals judged by the average detection $P$ value $(P<0.05)$, (ii) the fold-change was at least 1.5 and (iii) the $t$ test $P$ value was below 0.05 . The detection $P$ value is computed as a result of the Affymetrix data analysis by comparing the perfect match (PM) oligoprobes of a probe set with the mismatch (MM) oligoprobes with Wilcoxon's rank test. It judges whether the corresponding gene is expressed in the tissue under analysis or not. Additionally, we calculated a "Differential Expression Score" (DE-Score) for each differentially expressed gene that serves as a single coefficient combining the degree and significance of the detected expression dysregulation. It is defined as $\log 10(P$ value $){ }^{*} \log 2$ (foldchange)l. Here, "fold-change" corresponds to the average of the expression values in the fifty most and least infected animals and ' $P$ value' corresponds to the Student's $t$ test $P$ value. The DE-score allows prioritizing the identified candidate genes.

\section{Expression (e) QTL analysis}

Expression QTL analysis was performed based on the most $(n=50)$ and least $(n=50)$ susceptible pigs using the web-based application "Grid QTL" (Seaton et al. 2006). Susceptibility was evaluated with the help of the RHS of all 170 F2 pigs (Hoeltig et al. 2009; Reiner et al. 2014). Expression values of genes differentially expressed between the "resistant" and "susceptible" groups with a DE-Score of $\geq 2.3$ were used for eQTL analysis ensuring that physiologically interesting candidate genes with borderline scores were not excluded. Analyses were built on a least-squares method developed for crosses between inbred and outbred lines (Haley et al. 1994). The general linear model was pre-adjusted for the fixed effects of sex and study group. The age at infection was included as a covariate. Chromosome-wide and genome-wide significance levels were estimated by permutation tests (Churchill and Doerge 1994). F-values were $5.4(P \leq 0.05)$ and $7.7(P \leq 0.01)$ for chromosome-wide significance and 9.8 $(P \leq 0.05)$ for the genome-wide significance threshold. Positive A-values indicate that Hampshire alleles result in higher values than Landrace alleles, and vice versa.
Gene set enrichment and network analysis

Detection of relevant metabolic and gene regulatory networks associated with A. pleuropneumoniae resistance was performed by Gene Set Enrichment Analysis (GSEA, Subramanian et al. 2005).

Input data originated from transcriptome profiling based on Affymetrix microarrays (see above) to gather information about differentially expressed (or unchanged) genes. All genes that could be mapped with high confidence to the human genome and had a human gene symbol $(n=11248$ genes) were used as input, irrespective of their differential expression score. The gene sets that were used for the analysis originated from the default database of the GSEA tool (MSigDB) and the pathway sets provided by ConsensusPathDB (Kamburov et al. 2011).

The GSEA Java command-line tool (version 2.07) was executed with default parameters except that the $t$ test option was used as gene ranking metric.

In order to gain insight into relevant network interactions, the BioNet algorithm (Beisser et al. 2010) was applied. Based on a given network and the according node weights, it calculates a maximal scoring sub-network or "functional module". As input network, the human interactome was specified as it is represented in ConsensusPathDB (version 17); it consists of 101,613 binary interactions agglomerated from 22 different data resources. Finally, all genes of the microarray experiments that had a high-confidence human ortholog $(n=8,463)$ were collected and their $t$ test $P$ values were used for scoring the input network. Thereby genes that were more strongly differentially expressed exerted a higher impact during the generation of the functional module.

\section{Promoter analysis of differentially expressed genes}

Promoter sequences (up to $1 \mathrm{~kb}$ upstream of the transcription start site) of all porcine genes were downloaded from Ensembl BioMart (version 60). Repetitive parts of the sequences were masked with the "RepeatMasker open3.2.8" software (http://www.repeatmasker.org) using default parameters.

Promoter regions of differentially expressed genes were then analysed with the Amadeus motif discovery platform (Linhart et al. 2008). Because this software uses the upstream region of pig genes from Ensembl, reducing the number of differentially expressed probesets to those with an Ensembl-ID was necessary. First, all genes that were upregulated in diseased animals (134 probesets, 74 of these with Ensembl-ID) were used as input. Second, all differentially expressed genes, irrespective of the directionality of the dysregulation (171 probesets, 85 of these with Ensembl-ID), were used as input for the software. 
Table 1 Phenotypic scoring

\begin{tabular}{|c|c|c|c|c|c|c|}
\hline & \multicolumn{2}{|c|}{$\begin{array}{l}\text { "Resistant } \\
\text { pigs" } \\
(n=50)\end{array}$} & \multicolumn{2}{|c|}{$\begin{array}{l}\text { All pigs } \\
(n=170)\end{array}$} & \multicolumn{2}{|c|}{$\begin{array}{l}\text { "Susceptible } \\
\text { pigs" } \\
(n=50)\end{array}$} \\
\hline & Mean & SD & Mean & SD & Mean & SD \\
\hline pigs $(\%)$ & 0.0 & 0.0 & 7.0 & 25.6 & 14.0 & 35.1 \\
\hline Dissection score d7pi & 2.4 & 3.2 & 11.0 & 11.1 & 19.6 & 9.4 \\
\hline Reisolation score (RI) & 4.6 & 3.6 & 11.1 & 8.2 & 17.7 & 5.9 \\
\hline Sonographic score d0pi & 0.0 & 0.2 & 0.1 & 0.4 & 0.2 & 0.6 \\
\hline Sonographic score $\mathrm{d} 7 \mathrm{pi}$ & 0.2 & 0.5 & 41.6 & 58.8 & 82.9 & 59.0 \\
\hline Clinical score d7pi & 0.2 & 0.1 & 3.5 & 8.7 & 6.8 & 11.4 \\
\hline Radiographic score d7pi & 0.9 & 1.8 & 11.0 & 14.5 & 21.1 & 14.7 \\
\hline $\begin{array}{l}\text { Respiratory health score } \\
\text { (RHS) }\end{array}$ & 0.2 & 0.1 & 10.3 & 17.3 & 20.3 & 20.0 \\
\hline
\end{tabular}

d0pi, d7pi: day 0 post infection and day 7 post infection, respectively

The genes on the Affymetrix chip were defined as background set (all genes with an Ensembl gene ID, $n=6,441)$ and the software output consists of promoter sequence motifs that were enriched in differentially expressed genes in relation to the background set.

\section{Assignment of genes to the porcine genome}

Functional and positional candidate genes were assigned to chromosomes with command-line BLAT (version $32 \times 1$ ). More specifically, Affymetrix probe sequences downloaded from the Affymetrix website were aligned with genomic sequences (Sus scrofa version 9) downloaded from the Ensembl ftp-site (ftp://ftp.ensembl.org/pub/ release-56/fasta/sus_scrofa/dna).

The BLAT command-line options were as follows: blat -tileSize $=12 \quad$-stepSize $=6 \quad-$ maxGap $=0 \quad$-noTrimA -minIdentity $=100$. In order to minimize the chance of obtaining false positive hits, only alignments with $100 \%$ identity, i.e., with no mismatches, were accepted. Furthermore, the BLAT output was processed by removing alignments of probe sets with less than 9 of the 11 probes matching to the genome, a quality control measure recommended by the MicroArray Quality Control project (MAQC consortium 2006).

\section{Results}

\section{Clinical scoring}

For clinical QTL analysis (Reiner et al. 2014), lung samples of the 50 most and the 50 least resistant pigs out of 170 animals were used. Table 1 contrasts the phenotypes of both extreme groups and the entity of $170 \mathrm{~F} 2$ pigs. Extreme groups differed significantly in all traits $(P<0.001)$. Standard deviations show distinct variability in resistance/ susceptibility to A. pleuropneumoniae infection.

Identification of differentially expressed genes

Genome-wide transcriptome profiling resulted in 171 genes being differentially expressed. The list of the most strongly regulated genes is shown in Table 2 (the complete list is available as Supplementary Table 1). Among these genes are FCGR2B, C4A, SOD2, CHI3LI, IL10, IL18, and TCN1. All these genes were upregulated in diseased animals in comparison to healthy animals and are well known as response genes also in the context of other infectious diseases such as tuberculosis, pertussis, and malaria. With a 3.4 times upregulation in diseased pigs, SOD2 ("Superoxide dismutase 2 , mitochondrial") was one of the most strongly upregulated genes in our study. Among the differentially expressed genes were two cytokines: IL10 (Interleukin-10) and IL18 (Interleukin-18).

In order to visualize the discrimination of the 100 animals with the detected response gene set, we performed unsupervised clustering of the 171 differentially expressed probe sets and revealed the segregation of healthy and diseased animals, with moderate exceptions: Seven diseased animals were clustered together with 42 healthy animals, and eight healthy animals were clustered together with 43 diseased animals (Fig. 1). Also, genes that were up- or downregulated in diseased and healthy animals are separated in four large clusters. Three of these contain probe sets that were predominantly upregulated $(n=134)$ in diseased animals, while one cluster contains probe sets that were predominantly downregulated $(n=37)$ in diseased animals.

eQTL analysis

Based on a DE-Score of $>2.3,198$ genes were applied to eQTL analysis including all autosomes. Analysis mapped 193 eQTL for 105 differentially expressed genes, significant on at least a chromosome-wide level of $P \leq 0.05$ (the complete list is available as Supplementary Table 2). In 18 cases, these eQTL were located in close vicinity (cis) to the expressed gene, whereas in 175 cases eQTL were far away from the expressed gene, mostly on a different chromosome (trans). Chromosomes 1, 3 to 10, 12, and 15 harbored less than $10 \mathrm{eQTL}$ each; chromosomes $2,11,14$, and 16 to 18 carried between 11 and 18 eQTL each. The majority of eQTL (55) mapped to SSC13 (Table 3), from which 47 mapped to the region between 53 and $63 \mathrm{cM}$ and a further 6 eQTL were located between 116 and $128 \mathrm{cM}$. eQTL explained on average $14.1 \pm 5.5 \%$ of total $\mathrm{F} 2$ phenotypic variance, with a minimum of $10 \%$ and a maximum of 
Table 2 Top 30 differentially expressed genes

\begin{tabular}{|c|c|c|c|c|c|c|c|}
\hline Nr. & Probe_Set_ID & $\begin{array}{l}\log 2 \text { ratio } \\
\text { (diseased/healthy) }\end{array}$ & $P$ value & $\begin{array}{l}\text { DE- } \\
\text { score }\end{array}$ & Gene title & Gene symbol & HGNC \\
\hline 1 & Ssc.30077.1.A1_at & 1.77 & $6.12 \mathrm{E}-09$ & 14.5 & $\begin{array}{l}\text { Membrane-spanning 4-domains } \\
\text { subfamily A member 4A-like }\end{array}$ & LOC100525275 & - \\
\hline 2 & Ssc.11784.1.S1_at & 1.91 & $5.25 \mathrm{E}-07$ & 12.0 & TIMP metallopeptidase inhibitor 1 & TIMP1 & TIMP1 \\
\hline 3 & Ssc.8868.1.S1_at & 1.37 & $2.26 \mathrm{E}-09$ & 11.9 & $\begin{array}{l}\text { Fc fragment of IgG, low affinity IIb, } \\
\text { receptor }(\mathrm{CD} 32)\end{array}$ & FCGR2B & FCGR2B \\
\hline 4 & Ssc.17026.1.S1_at & 1.26 & $9.39 \mathrm{E}-10$ & 11.3 & Complement $\mathrm{C} 4$ & $\mathrm{C} 4$ & $\mathrm{C} 4 \mathrm{~A}$ \\
\hline 5 & Ssc.3706.1.S1_at & 1.76 & $5.14 \mathrm{E}-07$ & 11.1 & Superoxide dismutase 2 , mitochondrial & SOD2 & SOD2 \\
\hline 6 & Ssc.90.1.S1_at & 1.46 & $1.87 \mathrm{E}-07$ & 9.8 & $\begin{array}{l}\text { Chitinase 3-like } 1 \text { (cartilage glycoprotein- } \\
\text { 39) }\end{array}$ & CHI3L1 & CHI3L1 \\
\hline 7 & Ssc.22520.1.A1_at & -1.27 & $2.59 \mathrm{E}-08$ & 9.6 & Tripartite motif-containing 55 & TRIM55 & TRIM55 \\
\hline 8 & Ssc.29810.1.A1_at & -0.72 & $7.25 \mathrm{E}-14$ & 9.4 & Netrin 5 & NTN5 & NTN5 \\
\hline 9 & Ssc.148.1.S1_at & 1.08 & $3.47 \mathrm{E}-09$ & 9.2 & Interleukin 10 & IL10 & IL10 \\
\hline 10 & Ssc.20.1.S1_at & 0.78 & $1.68 \mathrm{E}-12$ & 9.1 & $\begin{array}{l}\text { Interleukin } 18 \text { (interferon-gamma- } \\
\text { inducing factor) }\end{array}$ & IL18 & IL18 \\
\hline 11 & Ssc.15379.1.S1_at & 1.58 & $6.21 \mathrm{E}-06$ & 8.2 & Diacylglycerol $O$-acyltransferase 2 & DGAT2 & DGAT2 \\
\hline 12 & Ssc.21802.1.S1_at & 1.67 & $1.73 \mathrm{E}-05$ & 8.0 & Chemokine (C-C motif) ligand 19 & CCL19 & CCL19 \\
\hline 13 & Ssc.806.1.A1_at & 0.64 & $4.93 \mathrm{E}-13$ & 7.9 & Ribosomal protein L23 & RPL23 & RPL23 \\
\hline 14 & Ssc.16234.1.S1_at & 1.41 & $3.12 \mathrm{E}-06$ & 7.8 & Haptocorrin & LOC396873 & TCN1 \\
\hline 15 & Ssc.719.1.S1_at & 3.33 & 0.0058 & 7.5 & $\begin{array}{l}\text { Alveolar macrophage-derived } \\
\text { chemotactic factor-II }\end{array}$ & AMCF-II & CXCL6 \\
\hline 16 & Ssc.6196.1.S1_at & 1.06 & $1.12 \mathrm{E}-07$ & 7.4 & Nucleoplasmin-3-like & LOC100153831 & NPM3 \\
\hline 17 & Ssc.22002.2.A1_at & 2.40 & 0.0009 & 7.2 & c-X-C Motif chemokine 13-like & LOC100524265 & CXCL13 \\
\hline 18 & Ssc.15674.1.A1_at & 2.65 & 0.0029 & 6.7 & Cathepsin L1-like & LOC100515919 & CTSL1 \\
\hline 19 & Ssc.8745.1.A1_at & 0.74 & $1.18 \mathrm{E}-09$ & 6.6 & - & - & SOAT1 \\
\hline 20 & Ssc.7996.1.A1_at & -0.98 & $3.24 \mathrm{E}-07$ & 6.4 & Cellular retinoic acid binding protein 1 & LOC100169745 & CRABP1 \\
\hline 21 & Ssc.19608.1.S1_at & -0.97 & $3.73 \mathrm{E}-07$ & 6.3 & Retinoid X receptor, gamma & RXRG & RXRG \\
\hline 22 & Ssc.9434.1.A1_at & 1.54 & 0.0001 & 6.0 & Uroplakin 1B & UPK1B & - \\
\hline 23 & Ssc.30027.1.A1_at & 1.89 & 0.0008 & 5.9 & - & - & CXCL11 \\
\hline 24 & Ssc.12514.1.A1_at & -0.60 & $1.32 \mathrm{E}-10$ & 5.9 & Stromelysin-3-like & LOC100153503 & - \\
\hline 25 & Ssc.8767.1.A1_at & 1.37 & $5.68 \mathrm{E}-05$ & 5.8 & - & - & CYP1B1 \\
\hline 26 & Ssc.19143.1.A1_at & 1.41 & $7.91 \mathrm{E}-05$ & 5.8 & - & - & SLC39A14 \\
\hline 27 & Ssc.22769.1.S1_at & 1.52 & 0.0002 & 5.7 & Duffy blood group, chemokine receptor & DARC & FY \\
\hline 28 & Ssc.28997.2.S1_at & 0.65 & $2.00 \mathrm{E}-09$ & 5.6 & - & - & - \\
\hline 29 & Ssc.4978.1.S1_at & 0.72 & $1.65 \mathrm{E}-08$ & 5.6 & CD14 molecule & CD14 & CD14 \\
\hline 30 & Ssc.6550.1.A1_at & -0.70 & $1.1 \mathrm{E}-08$ & 5.6 & Tetraspanin-7-like & LOC100526026 & TSPAN7 \\
\hline
\end{tabular}

Genes are ordered by DE-score, a score that combines the $\log 2$ ratio and test $P$ value ( $\log 2($ ratio $)|*| \log 10(P$ value $) \mid$. Where available, probe sets were annotated with human orthologous gene symbols (HGNC)

$57.3 \%$. Confidence intervals (CI) were generally wide with an average of $83.4 \pm 30.6 \mathrm{cM}$. However, the CI of 5 eQTL was below $10 \mathrm{cM}$ (minimum: $4.5 \mathrm{cM}$ ) and that of further $6 \mathrm{eQTL}$ was between 10 and $25 \mathrm{cM}$.

Cis-eQTL on chromosomes relevant for clinical QTL were detected for the genes TCN1 (SSC2), UPK1B, TF, TFRC, RAB6B, LOC100132553 (SSC13), and UBIQ (SSC18). Individual genes were associated with up to six eQTL.
Gene set enrichment analysis

Gene Set Enrichment Analysis (GSEA) was used to gain insight into functional implications of the transcriptome profiling results. The analysis revealed several important hints toward involved regulators and networks, like microRNAs, transcription factors, and pathways. 


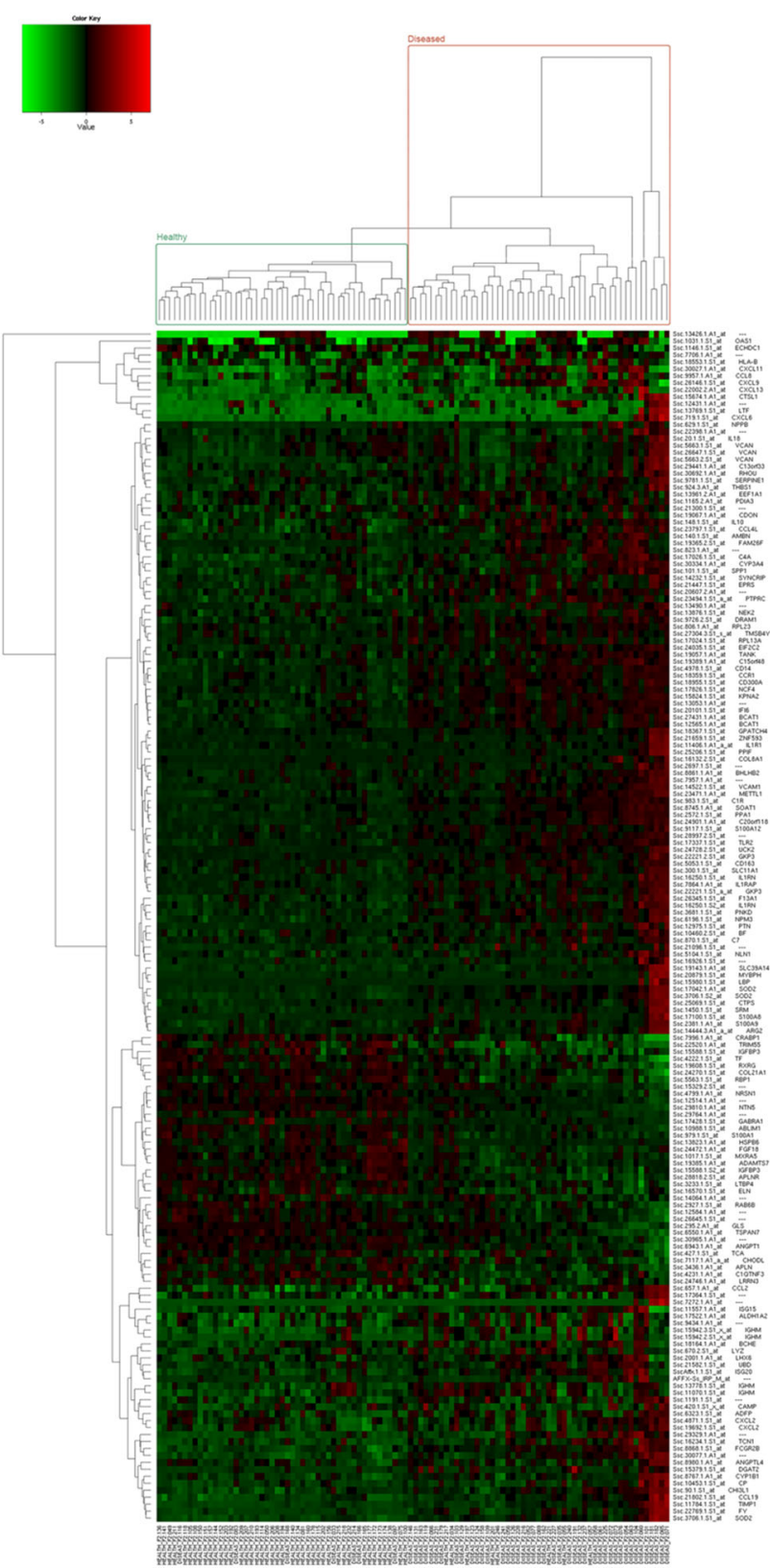

Fig. 1 Hierarchical clustering of 171 differentially expressed probe sets (generated with J-Express Pro; complete linkage, Euclidean distance). Columns represent samples, rows represent probe sets. Samples from healthy and diseased animals were separated into two clusters (green and red column bar labels), although some exceptions occurred (magenta column bar labels). If available, probe sets were annotated with human orthologous gene symbols (Color figure online)

\section{Chemical and genetic perturbations}

Examples for "Chemical and genetic perturbations" gene sets that were enriched in diseased animals are: "Tarte plasma_cell_vs_plasmablast_dn", an immune systemrelated process, "Manalo_hypoxia_dn", which represents a response to hypoxia, the deprivation of oxygen, and
"Wieland_up_by_hbv_infection", a response to infection with the hepatitis B virus.

On the other hand, one immune system-related term was enriched in healthy animals, and therefore downregulated in diseased animals: "Seki_inflammatory_response_lps_dn", which represents the response to lipopolysaccharides (LPS), molecules that are part of the outer membrane of gramnegative bacteria.

\section{Biocarta pathways}

Within the top 5 pathways from the Biocarta database that were enriched in diseased animals, three are essential pathways of the immune system: The NFKB-pathway, the complement-pathway, and the cytokine-pathway. Additionally, three immune system-relevant pathways were part of the top 20 enriched gene sets: The IL6-pathway, the IL10-pathway, and the Toll-pathway.

\section{GO terms}

Within the top 20 "Biological Process" GO terms, several immune system-related terms were found: "response_to_wounding", "inflammatory response", "defense response", "response to other organism", and "immune response". Regarding "Cellular Compartment" GO terms, many mitochondrial structures were enriched in diseased animals, a hint to the challenge of the respiratory system the infection poses to the animals. Also, some "Molecular Function" GO terms related to respiration and immune system, respectively, were enriched in diseased animals, e.g., "Intramolecular oxidoreductase activity", "Isomerase activity", or "Chemokine receptor binding".

\section{microRNA target sets}

Target sets of 32 miRNAs were significantly regulated (one target set upregulated in diseased animals; 31 target sets downregulated in diseased animals; False discovery rate (FDR) $<0.25$ ). Only results from miRNAs are shown, which have both a high enrichment score and information about the chromosomal location of their pig orthologs.

MicroRNAs that were presumably upregulated include $m i R-10 a / b$, located on pig chromosomes 12 and 15 , respectively, and miR-324-3p, located on pig chromosome 12 (Fig. 2).

\section{Transcription factor targets}

GSEA revealed several transcription factor target sets that were significantly enriched. The following transcription factors were located on chromosome 2 , which is one of the genomic locations that were highlighted in the eQTL 
Table 3 eQTL on SSC13 sorted by position

\begin{tabular}{|c|c|c|c|c|c|c|c|c|c|c|c|c|}
\hline Gene (SSC) & $\begin{array}{l}\text { SSC } \\
\text { eQTL }^{\text {a }}\end{array}$ & $\begin{array}{l}\text { POS } \\
(\mathrm{cM})^{\mathrm{b}}\end{array}$ & $F$ value $^{\mathrm{c}}$ & $\begin{array}{l}\% \mathrm{Var} \\
\mathrm{F} 2^{\mathrm{d}}\end{array}$ & Mean $^{\mathrm{e}}$ & $\mathrm{SD}^{\mathrm{f}}$ & $A^{g}$ & $\mathrm{SD} \mathrm{A}^{\mathrm{h}}$ & $\mathrm{D}^{\mathrm{i}}$ & $S D D^{j}$ & $\mathrm{CI}^{\mathrm{k}}$ & $\delta \mathrm{CI}^{1}$ \\
\hline IGHAT (1) & 13 & 22 & 6.4 & 12.5 & 3216.1 & 334.8 & 771.3 & 329.7 & -1524.8 & 507.9 & $15.5-122.5$ & 97 \\
\hline UPK1B (13) & $13 \mathrm{c}$ & 27 & 6.1 & 11.9 & 139.4 & 27.4 & -75.8 & 26.5 & -61.9 & 42.0 & $0-128$ & 128 \\
\hline CD300C (12) & 13 & 53 & 8.3 & 15.5 & 34.1 & 2.23 & -8.2 & 2.2 & -4.5 & 3.1 & $27.5-128$ & 100.5 \\
\hline PNKD (X) & 13 & 53 & 6.1 & 11.9 & 16.4 & 1.6 & -4.9 & 1.6 & -2.7 & 2.2 & $1-116$ & 115 \\
\hline TMSL3 (X) & 13 & 53 & 10.8 & 19.4 & 83.0 & 5.2 & -22.1 & 5.2 & 16.0 & 7.3 & $47.5-116$ & 68.5 \\
\hline FLJ11259 (5) & 13 & 56 & 5.7 & 11.2 & 40.7 & 4.53 & -15.2 & 4.5 & 6.9 & 6.3 & $6-116$ & 110 \\
\hline TF (13) & $13 \mathrm{c}$ & 56 & 60.4 & 57.3 & 1463.6 & 90.3 & 924.1 & 89.7 & 17.1 & 125.3 & $46.5-57.5$ & 11 \\
\hline RAB6B (13) & $13 \mathrm{c}$ & 57 & 26.9 & 37.4 & 59.9 & 4.7 & 29.5 & 4.3 & 0.1 & 6.0 & $49-66$ & 17 \\
\hline S100A9 (4) & 13 & 57 & 7.7 & 14.7 & 5922.2 & 855.4 & -1970.0 & 848.1 & -2145.1 & 1159.6 & $12.5-116$ & 103.5 \\
\hline S100Z (4) & 13 & 57 & 8.6 & 16.0 & 38.9 & 3.8 & -12.5 & 3.8 & -4.1 & 5.2 & $19-116$ & 97 \\
\hline CCL19 (10) & 13 & 58 & 5.6 & 11.0 & 761.8 & 272.8 & -507.1 & 270.4 & -482.5 & 358.0 & $7-110.5$ & 103.5 \\
\hline CSF2RB (5) & 13 & 58 & 7.2 & 13.7 & 25.8 & 2.5 & -7.8 & 2.5 & -0.6 & 3.3 & $19-128$ & 109 \\
\hline CTPS (6) & 13 & 58 & 6.8 & 13.1 & 43.0 & 9.7 & -21.1 & 9.6 & -17.2 & 12.7 & $10-110$ & 100 \\
\hline NPM3 (14) & 13 & 58 & 7.2 & 13.7 & 305.7 & 65.5 & 182.0 & 65.0 & -57.9 & 86.0 & $8-77$ & 69 \\
\hline TMEM158 (8) & 13 & 58 & 12.9 & 22.3 & 194.5 & 51.5 & -193.8 & 51.1 & -57.1 & 67.6 & $26-65$ & 39 \\
\hline YDL201w (5) & 13 & 58 & 5.5 & 10.9 & 41.4 & 5.66 & -11.1 & 5.6 & -9.0 & 7.4 & $5-128$ & 123 \\
\hline ANGPT1 (4) & 13 & 59 & 8.3 & 15.6 & 250.5 & 25.7 & 69.6 & 25.5 & 23.5 & 32.4 & $27-116$ & 89 \\
\hline CD163 (14) & 13 & 59 & 5.7 & 11.3 & 3981.7 & 448.6 & -1156.4 & 445.4 & -78.9 & 565.2 & $2-128$ & 126 \\
\hline COL21A1 (7) & 13 & 59 & 8.1 & 15.3 & 721.8 & 61.6 & 245.1 & 61.3 & -160.9 & 77.8 & $11-128$ & 117.0 \\
\hline DARC (4) & 13 & 59 & 7.0 & 13.5 & 29.5 & 9.4 & -16.5 & 9.3 & -18.2 & 11.9 & 19-116 & 97 \\
\hline GK (15) & 13 & 59 & 5.6 & 11.0 & 524.3 & 73.6 & -107.7 & 73.1 & -137.5 & 92.7 & $5.5-116$ & 110.5 \\
\hline SERPINB2 (1) & 13 & 59 & 5.3 & 10.5 & 28.71 & 15.0 & -24.0 & 15.0 & -23.7 & 19.0 & $3-110$ & 107 \\
\hline SLC39A14 (14) & 13 & 59 & 7.6 & 14.5 & 443.7 & 136.8 & -255.6 & 135.9 & -269.4 & 172.4 & $10-65$ & 55 \\
\hline SRM (6) & 13 & 59 & 8.0 & 15.1 & 30.5 & 7.84 & -16.3 & 7.8 & -14.0 & 9.9 & $13-64$ & 51 \\
\hline UCK2 (4) & 13 & 59 & 5.9 & 11.5 & 47.9 & 6.9 & -13.8 & 6.9 & -8.5 & 8.7 & $9-116$ & 107 \\
\hline ARG2 (13) & 13 & 60 & 9.4 & 17.2 & 39.9 & 9.1 & -19.0 & 9.1 & -15.2 & 10.9 & $40.5-64$ & 23.5 \\
\hline C13orf33 (11) & 13 & 60 & 9.45 & 17.4 & 745.5 & 196.3 & -373.8 & 195.7 & -379.9 & 236.1 & $12-109$ & 97.5 \\
\hline CHI3L1 (9) & 13 & 60 & 6.4 & 12.4 & 5399.6 & 1380.5 & -2160.2 & 1374.8 & -2175.6 & 1658.6 & $8-116$ & 108 \\
\hline F13A1 (7) & 13 & 60 & 9.1 & 16.9 & 693.8 & 151.0 & -373.8 & 150.5 & -166.0 & 181.5 & $43-128$ & 85 \\
\hline $\begin{array}{l}\text { LOC1002 } 91908 \\
\text { (17) }\end{array}$ & 13 & 60 & 11.6 & 20.5 & 142.5 & 22.3 & -50.6 & 22.2 & -43.1 & 26.8 & $50-65$ & 15 \\
\hline MXI (1) & 13 & 60 & 6.5 & 12.6 & 37.3 & 3.4 & 11.8 & 3.4 & -7.0 & 4.1 & $29-128$ & 99 \\
\hline PPIF (14) & 13 & 60 & 8.8 & 16.4 & 56.7 & 14.6 & -28.7 & 14.5 & -24.9 & 17.5 & $43.5-65$ & 21.5 \\
\hline SOD2 (1) & 13 & 60 & 7.9 & 15.0 & 2267.6 & 615.0 & -1158.3 & 612.2 & -982.6 & 738.7 & $20.5-67$ & 46.5 \\
\hline TIMP1 (X) & 13 & 60 & 8.4 & 15.7 & 1856.2 & 712.0 & -1351.1 & 709.0 & -1200.7 & 855.4 & $13.5-65$ & 51.5 \\
\hline VCAN (2) & 13 & 60 & 8.5 & 15.8 & 30.7 & 8.89 & -17.0 & 8.9 & -15.0 & 10.7 & $9-113$ & 104 \\
\hline IGFBP3 (18) & 13 & 61 & 7.6 & 14.5 & 116.0 & 15.4 & 56.3 & 15.4 & -61.7 & 17.6 & $54.5-128$ & 73.5 \\
\hline MS4A4A (2) & 13 & 61 & 7.6 & 14.4 & 109.3 & 37.8 & -75.2 & 37.7 & -41.2 & 43.1 & $14-128$ & 114 \\
\hline VCAM1 (4) & 13 & 61 & 6.7 & 12.9 & 2774.3 & 524.2 & -1024.7 & 523.7 & -473.0 & 597.4 & $19-116$ & 97 \\
\hline CD276 (6) & 13 & 62 & 6.3 & 12.4 & 8.5 & 2.0 & -3.3 & 2.0 & -2.3 & 2.2 & $11.5-128$ & 116.5 \\
\hline CFB (7) & 13 & 62 & 6.4 & 12.5 & 59.5 & 11.0 & -15.1 & 11.0 & -15.6 & 11.8 & $18-123$ & 105 \\
\hline CTSL2 (10) & 13 & 62 & 8.0 & 15.1 & 116.2 & 64.0 & -107.0 & 64.0 & -93.0 & 68.9 & $9-67$ & 58 \\
\hline CXCL6 (8) & 13 & 62 & 5.9 & 11.6 & 166.8 & 111.3 & -154.4 & 111.3 & -144.1 & 119.8 & $10-108$ & 98 \\
\hline CYP1B1 (3) & 13 & 62 & 9.9 & 18.1 & 569.7 & 186.8 & -363.8 & 186.8 & -283.8 & 201.0 & $18-64$ & 46 \\
\hline IL1RAP (3) & 13 & 62 & 6.8 & 13.1 & 469.5 & 72.3 & -120.9 & 72.3 & -85.9 & 77.8 & $0-77$ & 77 \\
\hline IL1RN (15) & 13 & 62 & 6.4 & 12.4 & 369.1 & 82.0 & -129.1 & 82.0 & -98.8 & 88.3 & $26.5-128$ & 101.5 \\
\hline $\begin{array}{l}\text { LOC100132553 } \\
\text { (13) }\end{array}$ & $13 \mathrm{c}$ & 62 & 7.5 & 14.3 & 82.1 & 33.6 & -56.0 & 33.6 & -45.2 & 36.2 & $9.5-65$ & 55.5 \\
\hline
\end{tabular}


Table 3 continued

\begin{tabular}{|c|c|c|c|c|c|c|c|c|c|c|c|c|}
\hline Gene (SSC) & $\begin{array}{l}\text { SSC } \\
\mathrm{eQTL}^{\mathrm{a}}\end{array}$ & $\begin{array}{l}\text { POS } \\
(\mathrm{cM})^{\mathrm{b}}\end{array}$ & $F$ value $^{\mathrm{c}}$ & $\begin{array}{l}\% \text { Var } \\
F 2^{\mathrm{d}}\end{array}$ & Mean $^{\mathrm{e}}$ & $\mathrm{SD}^{\mathrm{f}}$ & $A^{g}$ & $\mathrm{SD} \mathrm{A}^{\mathrm{h}}$ & $\mathrm{D}^{\mathrm{i}}$ & $S D D^{j}$ & $\mathrm{CI}^{\mathrm{k}}$ & $\delta \mathrm{CI}^{1}$ \\
\hline LOC728320 (1) & 13 & 62 & 9.7 & 17.7 & 97.5 & 50.9 & -90.9 & 50.9 & -84.5 & 54.8 & $12-64$ & 52 \\
\hline CRABP1 (7) & 13 & 63 & 7.3 & 13.9 & 120.8 & 15.5 & 59.0 & 15.5 & -48.5 & 17.7 & $20-116$ & 96 \\
\hline TCN1 (2) & 13 & 63 & 5.8 & 11.4 & 36.4 & 13.2 & -27.4 & 13.2 & -6.4 & 15.1 & $2-128$ & 126 \\
\hline TSPAN7 (X) & 13 & 116 & 5.7 & 11.3 & 49.2 & 2.62 & 6.7 & 2.6 & -10.6 & 4.1 & $0-81.5$ & 81.5 \\
\hline SFTPD (14) & 13 & 124 & 8.8 & 16.4 & 4.1 & 0.0 & -0.1 & 0.0 & 0.0 & 0.0 & $1-128$ & 127 \\
\hline TFRC(13) & $13 \mathrm{c}$ & 125 & 6.5 & 12.6 & 3.7 & 0.0 & 0.0 & 0.0 & 0.0 & 0.0 & $0-128$ & 128 \\
\hline AEN (1) & 13 & 128 & 7.3 & 13.9 & 82.0 & 12.7 & -27.1 & 12.7 & -39.9 & 15.6 & $12-128$ & 116 \\
\hline HS2ST1 (9) & 13 & 128 & 5.5 & 10.9 & 2891.2 & 188.3 & -326.1 & 188.3 & -544.3 & 232.7 & $19.5-128$ & 108.5 \\
\hline STAT3 (15) & 13 & 128 & 6.1 & 11.9 & 1378.4 & 110.8 & -130.2 & 110.8 & -396.3 & 137.7 & $17-128$ & 111 \\
\hline
\end{tabular}

${ }^{a}$ Chromosomal location of the eQTL; c: cis-eQTL

b Position on the chromosome in centiMorgan

${ }^{\mathrm{c}} F$ values of the eQTL; thresholds for chromosome-wide significance were $5.4(P \leq 0.05)$ and $7.7(P \leq 0.01)$, respectively. The threshold for genome-wide significance $(P<0.05)$ was 9.8

${ }^{\mathrm{d}}$ Percentage of F2-phenotypic variance explained by the eQTL

e Overall mean of the trait

${ }^{\mathrm{f}}$ Overall standard deviation of the trait

g Additive effects of eQTL; positive values indicate that Hampshire alleles result in higher values for the trait than Landrace alleles and vice versa

h Standard deviation of A

${ }^{\mathrm{i}}$ Dominance effects of eQTL

${ }^{\mathrm{j}}$ Standard deviation of $\mathrm{D}$

k $95 \%$ Confidence interval of the eQTL's position (cM)

${ }^{1}$ Span of confidence interval

A

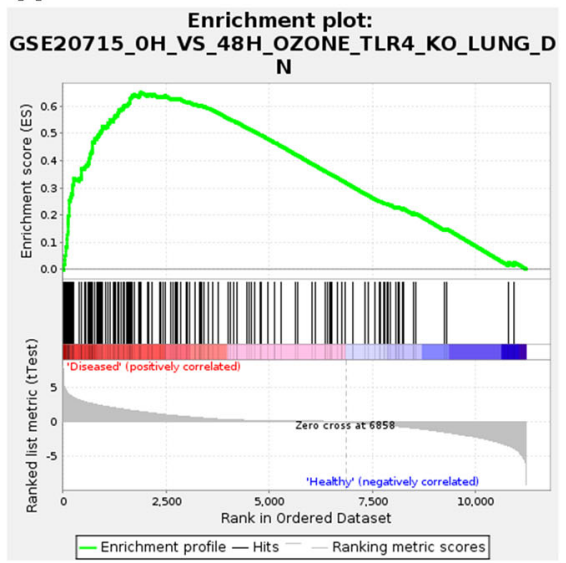

B

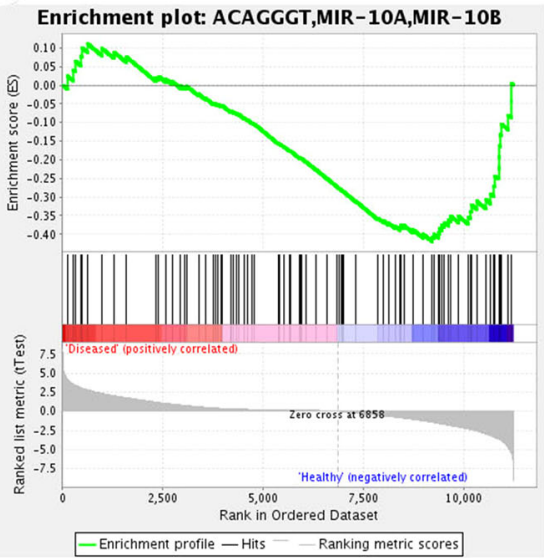

C



Fig. 2 a Immunologic signature related to TLR4-dependent genes in mouse lung tissue. b Target gene set of $m i R-10 a / b$ (pig orthologs located on chromosomes 12 and 15, respectively); the target genes were downregulated in diseased animals. c Target gene set of $m i R$ 324-3p (pig ortholog located on chromosome 12); the target genes were downregulated in diseased animals analysis: NR1H3 (13.3 Mb), TEAD1 (43.2 Mb), and TCF3 (46.6 Mb). The target genes of both TEAD1 and TCF3 were downregulated in diseased animals.
Another interesting transcription factor whose target genes were upregulated in diseased animals is ARNT1, located on porcine chromosome 4. 
A
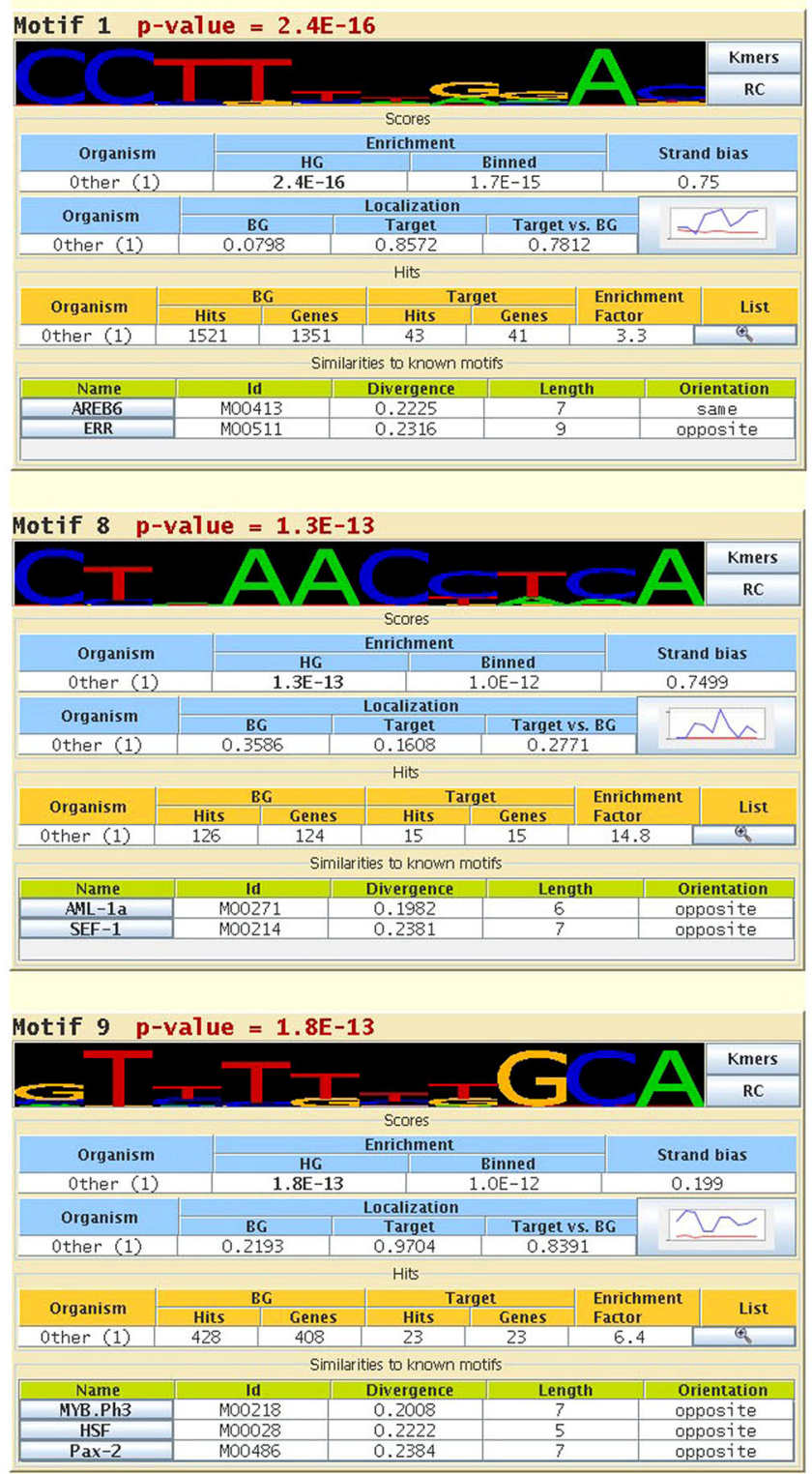

Fig. 3 Based on differentially expressed genes, possible transcription factor binding sites were identified (Software: Amadeus). Either only upregulated genes (a), or all regulated genes (b) were used as input for the software. Transcription factors that are known to bind to the

Transcription factor identification by promoter sequence analysis

Promoter sequence analysis of genes that were upregulated in diseased animals revealed three transcription factors that were located on chromosomes exhibiting significant eQTL (Fig. 3a): Estrogen-related receptor alpha ("ESRRA", located on $\mathrm{SSC} 2,6.2 \mathrm{Mb}[\sim 16 \mathrm{cM}])$, runt-related transcription factor 1 ("RUNX1", located on SSC13, $140.0 \mathrm{Mb}[\sim 65 \mathrm{cM}]$ ), and paired box 2 ("PAX2", SSC14, $116.8 \mathrm{Mb}[\sim 48 \mathrm{cM}])$.
B
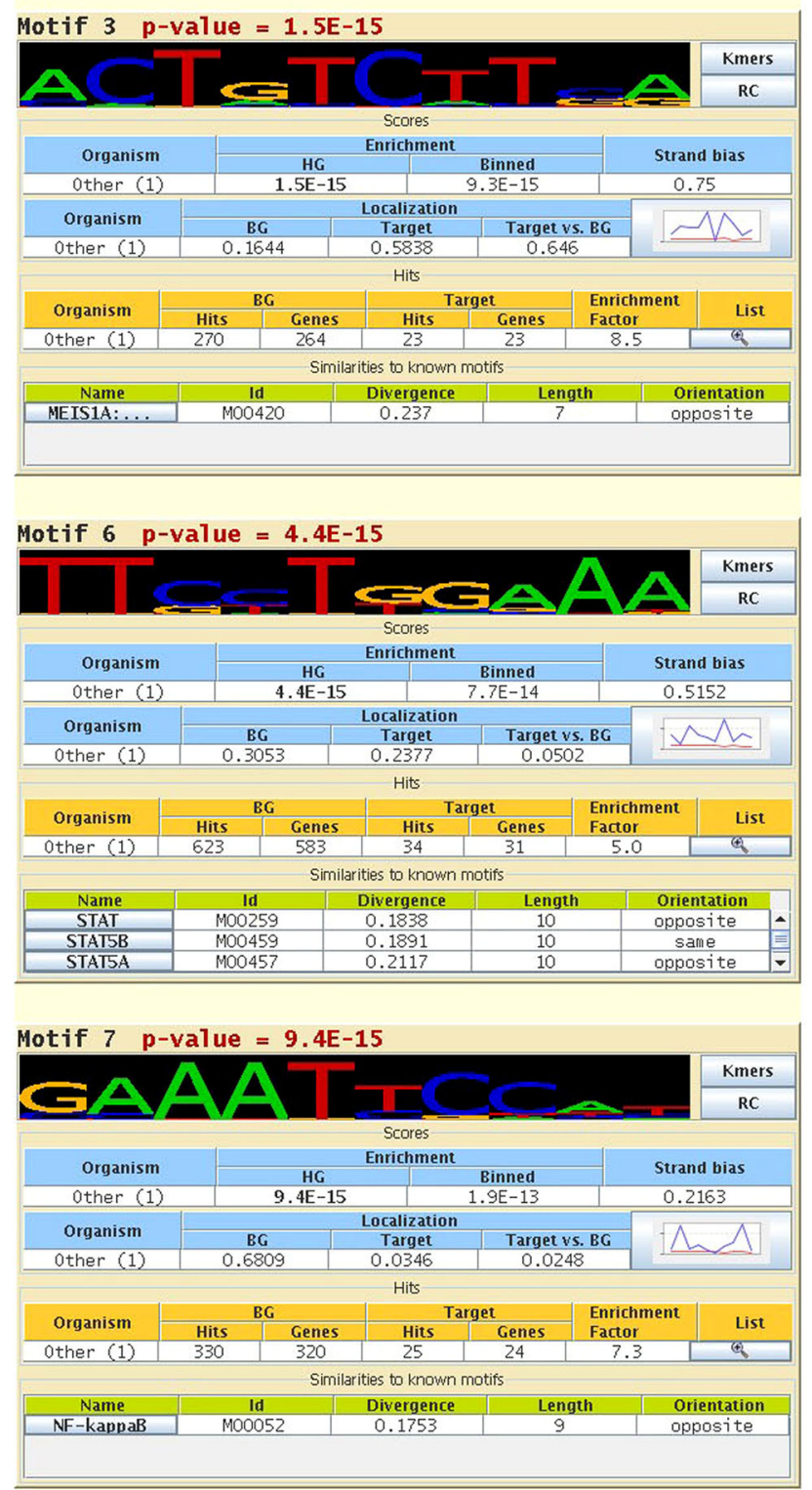

shown motifs are: AREB6 (=ZEB1), ERR (=ESRRA), AML-1a (=RUNX1), SEF-1, MYB.Ph3, HSF (=HSTF), Pax-2, MEIS1A: HOXA9, STAT5A, STAT5B, and NFKB

Promoter sequence analysis with all differentially expressed genes yielded different results (Fig. 3b).

Two transcription factors were found that are known to be of specific importance in immune system-related gene regulation: NF-kappa-B and the STAT gene family. Several of the members of this gene family are located on pig chromosome 12 around $20 \mathrm{Mb}[\sim 22 \mathrm{cM}]$ : STAT3, STAT5A, and STAT5B.

Also, the heterodimer MEIS1A:HOXA9, a member of the HOX gene family, was identified as a potential transcription factor. The gene of the subunit HOXA9 is located 


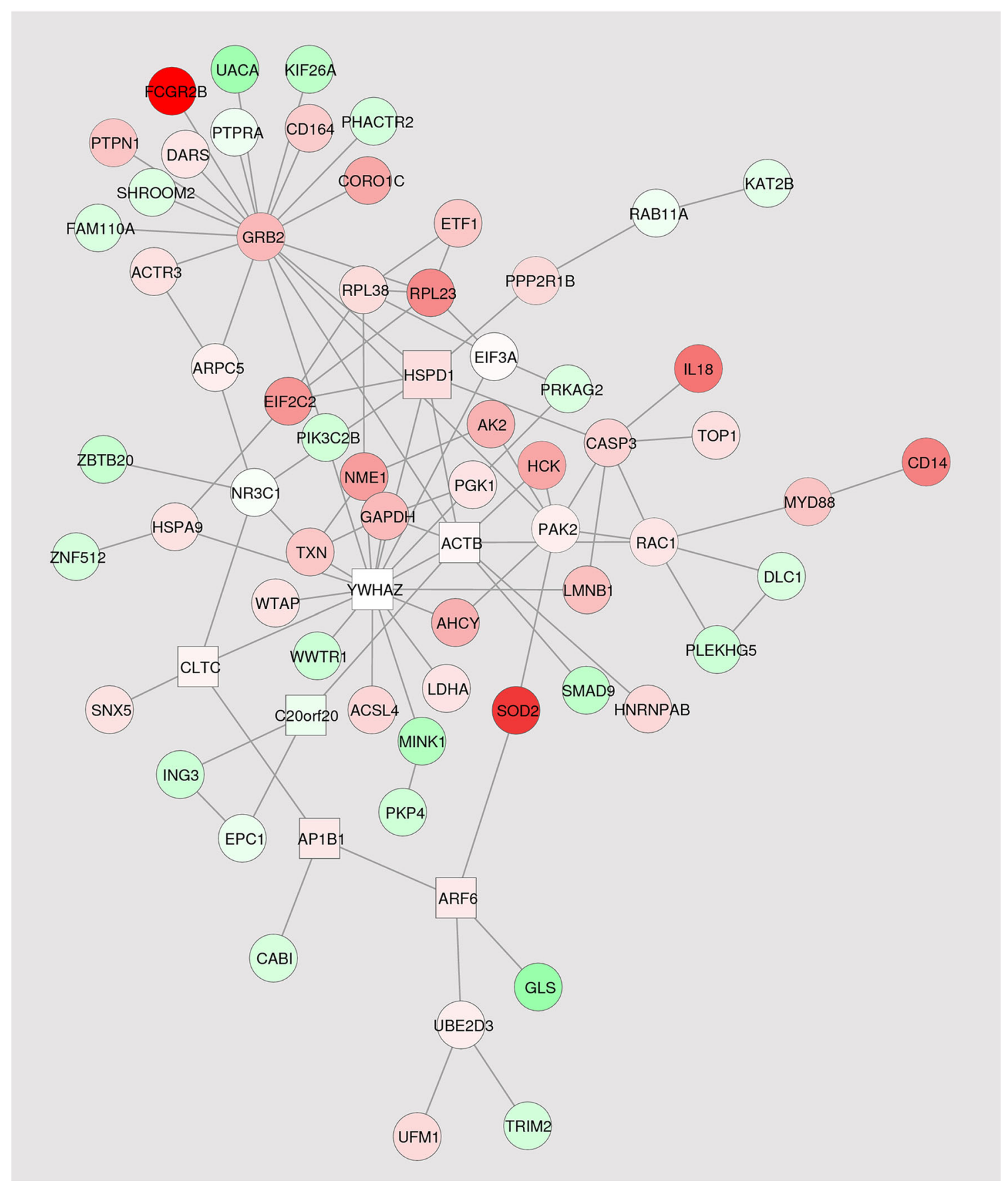

Fig. 4 The BioNet software was used to calculate a maximal scoring subnetwork based on the $P$ values of the microarray results. Green nodes represent genes downregulated in diseased animals; red nodes represent

on porcine chromosome 18 (44.2 $\mathrm{Mb}[\sim 57 \mathrm{cM}])$, which was shown to be an important location in the eQTL analysis.

\section{Network analysis}

Network analysis resulted in a maximal scoring sub-network consisting of 69 genes (Fig. 4; Supplementary Table 3). Only seven of these genes were significantly differentially genes upregulated in diseased animals. In order to utilize the human proteinprotein interaction network taken from ConsensusPathDB, the analysis was conducted with human orthologs of pig probesets (Color figure online)

expressed showing the complementarity of the network approach with the single gene analysis. The remaining 62 genes were regulated to a lesser extent, but still represent important additional information regarding pathways and possible regulatory interactions.

Therefore, chromosomal locations of all sub-network genes were examined in order to find consistencies with predicted eQTL locations, especially those located on 
Table 4 Candidate genes

\begin{tabular}{|c|c|c|c|c|c|c|}
\hline Probeset ID & $\begin{array}{l}\text { Gene symbol } \\
\text { (human) }\end{array}$ & $\begin{array}{l}\text { Ensembl ID } \\
\text { (human) }\end{array}$ & $\begin{array}{l}\log 2 \text { ratio (diseased/ } \\
\text { healthy) }\end{array}$ & Chromosome & $\begin{array}{l}\text { Location } \\
(\mathrm{Mb})\end{array}$ & $\begin{array}{l}\text { Nearby eQTL } \\
\text { marker }\end{array}$ \\
\hline Ssc.13826.1.S1_at & LDHA & ENSG00000134333 & 0.24 & 2 & 38.0 & \\
\hline Ssc.9089.1.A1_at & HNRNPAB & ENSG00000197451 & 0.29 & 2 & 69.4 & \\
\hline Ssc.21730.1.S1_at & LMNB1 & ENSG00000113368 & 0.41 & 2 & 117.6 & SWR345 (114 cM) \\
\hline Ssc.6041.2.A1_at & ETF1 & ENSG00000120705 & 0.37 & 2 & 127.6 & SWR345 (114 cM) \\
\hline Ssc.6798.1.S1_at & HSPA9 & ENSG00000113013 & 0.24 & 2 & 127.6 & SWR345 (114 cM) \\
\hline Ssc.4978.1.S1_at & CD14 & ENSG00000170458 & 0.71 & 2 & 129.4 & SWR345 (114 cM) \\
\hline Ssc.21577.1.A1_at & NR3C1 & ENSG00000113580 & -0.14 & 2 & 131.6 & SWR345 (114 cM) \\
\hline Ssc.19334.1.S1_at & GRB2 & ENSG00000177885 & 0.44 & 12 & 4.2 & S0143 (6.6 cM) \\
\hline Ssc.28256.1.A1_at & RPL38 & ENSG00000172809 & 0.27 & 12 & 4.9 & S0143 (6.6 cM) \\
\hline Ssc.19546.1.S1_at & NME1 & ENSG00000011052 & 0.58 & 12 & 25.1 & \\
\hline Ssc.7584.1.S1_at & CLTC & ENSG00000141367 & 0.16 & 12 & 34.1 & \\
\hline Ssc.16696.1.S1_at & MINK1 & ENSG00000141503 & -0.47 & 12 & 49.2 & \\
\hline Ssc.6463.1.A1_at & MYD88 & ENSG00000172936 & 0.39 & 13 & 18.9 & \\
\hline Ssc.15308.1.A1_at & WWTR1 & ENSG00000018408 & -0.35 & 13 & 73.1 & \\
\hline Ssc.2878.1.A1_at & PAK2 & ENSG00000180370 & 0.19 & 13 & 100.5 & \\
\hline Ssc.6995.1.A1_at & ZBTB20 & ENSG00000181722 & -0.38 & 13 & 108.6 & \\
\hline Ssc.3067.1.S1_at & PRKAG2 & ENSG00000106617 & -0.28 & 18 & 5.0 & \\
\hline Ssc.26415.1.A1_at & ING3 & ENSG00000071243 & -0.35 & 18 & 24.1 & \\
\hline
\end{tabular}

Selection of functional module genes that could be assigned to one of the chromosomes with eQTL hotspots (SSC2, SSC12, SSC13, SSC18). Pig probe sets were annotated with orthologous human gene symbols and Ensembl IDs

chromosomes 2, 12, 13, and 18 (Table 4). For example, seven genes were located on SSC2 and SSC12, five of which lay nearby the marker SWR345 on SSC2 (LMNB1, ETF1, HSPA9, CD14, NR3C1). Two genes (GRB2, RPL38) were found that are located near the marker S0143 on SSC12.

\section{Discussion}

Enrolling the genetic architecture of disease resistance has become a central branch of research worldwide. Numerous models of host pathogen interactions have shown evidence for breed or line differences. Detection of underlying gene variants, however, remains a rare event.

Recent evidence for genetic resistance/susceptibility of pigs to A. pleuropneumoniae, a serious factor in worldwide pig production, comes from direct line comparisons (Hoeltig et al. 2009; Benga et al. 2009; Danilowicz et al. 2009; Kahlisch et al. 2009) and two QTL studies (Gregersen et al. 2010; Reiner et al. 2014). Gregersen et al. (2010) mapped QTL for chronic pleuritis in a vast number of slaughter pigs, however, with minor accuracy regarding field phenotypes. The other study focused essentially on two pig lines (Hampshire and German Landrace lines) with most pronounced differences in clinical, pathological, and microbiological outcome after challenge with a well-characterized
A. pleuropneumoniae serotype 7 strain. Precise phenotyping of challenged pigs was the major advantage of this study; the disadvantage, however, lay in the relative small animal numbers. Thus, in spite of good agreement regarding chromosomal areas mapped by Gregersen et al. (2010) and Reiner et al. (2014), confidence intervals remain large with hundreds of potential candidate genes. The remaining studies have provided evidence for groups of candidates (e.g., TF, HP, FETUA), however, on a methodically restricted basis.

The present study applied a set of functional studies (transcriptomics, expression QTL analysis, pathway analysis, gene set enrichment analysis, promoter analysis and network analysis) on the 50 most and the 50 least susceptible out of 170 pigs from the clinical QTL study by Reiner et al. (2014). The idea was to identify candidate genes that were located in the gross regions of clinical QTL and at the same time were either differentially expressed and linked to a cis-eQTL, or could be deduced from network, gene set enrichment, or promoter analysis. The overall goal was to prioritize candidate genes for further fine mapping of those gene variants causal for different susceptibility/resistance to $A$. pleuropneumoniae.

The study of Reiner et al. (2014) revealed significant QTL for clinical, pathological, and microbiological parameters of F2 pigs challenged with $A$. pleuropneumoniae. The effects 
were mapped to SSC2 (peak at $114 \mathrm{cM}$; CI 100-114 cM), SSC6 (peak at 28-30 cM; CI 14-109 cM), SSC12 (peak at 1-20 cM; CI 0-93.5 cM), SSC13 (peak at $56 \mathrm{cM;} \mathrm{CI}$ 0-128 cM), SSC16 (peak at $24 \mathrm{cM}$; CI0-84 cM), SSC17 (peak at $7 \mathrm{cM}$; CI 3-91 cM), and SSC18 (peak at 0-6 cM; CI $0-58 \mathrm{cM}$ ). The results for SSC2, 12, 13, and 18 were widely consistent with recent data published by Gregersen et al. (2010) on QTL for chronic pleuritis in slaughter pigs, although peaks did not agree very consistently, and QTL differed seriously between families (Gregersen et al. 2010).

Nevertheless, both studies indicate the importance of SSC2, 12, 13, and 18 with regard to A. pleuropneumoniae susceptibility. Out of 170 F2 pigs, used for the QTL study of Reiner et al. (2014), lung samples of the 50 most and the 50 least susceptible pigs according to the RHS (Hoeltig et al. 2009) were selected for the present study. Pigs showed a pronounced variability in clinical, pathological, and microbiological phenotypes with significant differences between the most and least susceptible groups.

A porcine $24 \mathrm{~K}$-cDNA microarray identified 171 differentially expressed transcripts (DE-score $>3$ ). Quantitative variation of 198 transcripts (DE-score $>2.3$ ) identified 193 eQTL, 18 of them (9.3\%) in the chromosomal region of the respective gene (cis). This means that $90.7 \%$ of DE genes were differentially expressed because of trans-acting regulatory genes on other chromosomes. Thus, the causative gene variants have to be searched for in other, initially unknown genes. It remains unclear how many of the $9.3 \%$ genes with the effects of the same chromosome are because of a distinct gene in the neighborhood of the regulated gene. Additionally, several of the markers identified by microarray or eQTL analyses in the F2 population have been cross-validated to correlate with severity of the disease in the parental Landrace strain using additional microarray and qRT-PCR data (Supplementary Fig. 1). Among these, in particular IL10 and TLR4 showed a high correlation with disease progression.

The most prominent eQTL ( $F$ value 60.5 ) explained more than $57 \%$ of total $\mathrm{F} 2$ variance for transferrin mRNA. This eQTL peaked on SSC13 ( 90 Mb; CI $\sim 35 \mathrm{Mb}-$ $90 \mathrm{Mb})$ near the chromosomal region of the transferrin gene (TF, 82.4 Mb). Thus, the responsible QTN might be expected within the TF gene. The existence of SNPs within the TF gene has already been reported (Danilowicz et al. 2009), although the variant responsible for this eQTL still awaits identification. Transferrin is an important factor in pleuropneumonia. The outcome of disease depends to a high degree on a strainś ability to utilize porcine transferrin for its own iron acquisition (Chiers et al. 2010). The DEScore for TF, however, was below 3 (2.7). Thus, the transferrin effect on A. pleuropneumoniae susceptibility does not seem to be the only essential factor for A. pleuropneumoniae susceptibility in the F2 family.
A second cis-eQTL was identified further terminal $(\sim 208 \mathrm{Mb})$ for the transferrin receptor gene (TFRC; $143 \mathrm{Mb}$ ). TFRC has been in focus with Enterotoxigenic Escherichia coli F4 (ETEC F4) resistance in pig. Detected SNPs were linked with the QTL, but were excluded as QTN (Wang et al. 2007). Further research is needed to evaluate its role in susceptibility to A. pleuropneumoniae.

Two further cis-eQTL on SSC13 were associated with RAB6B (member 6b of the ras oncogene family) and UPK1B (uroplakin 1b). Rab proteins are small GTPases that are key regulators of intracellular membrane traffic (Wanschers et al. 2008). Uroplakin is part of the innate immune system, especially important in urinary tract infection by gram-negative bacteria (Ertan et al. 2010).

The most interesting aspect of SSC13, however, is a hotspot of gene regulation harboring 47 trans-eQTL in the region between Sw882 and Sw1979 (i.e., 53-63 cM and 87.8-127.5 Mb, respectively).

Regarding the clear role of transferrin and its receptor in metabolism, these genes are no candidates for this transband regulator(s). However, no further cis-eQTL was detected in this region. If the missing $\mathrm{QTN}(\mathrm{s})$ in this region was/were located within transcribed regions of one or more genes, we would not expect to find such a gene as eQTL. Nevertheless regulatory (trans) effects of such genes on other genes could be expected.

RUNX1 (located on SSC13, $140.0 \mathrm{Mb}$ ), arises as a candidate gene for this region from the transcription factor identification by promoter sequence analysis. Its protein product forms a heterodimer with $\mathrm{CBFB}$, which binds to a number of enhancers and promoters, including murine leukemia virus, polyomavirus enhancer, T-cell receptor enhancers, LCK, IL-3, and GM-CSF promoters (de Bruijn and Speck 2004). Additionally, it acts synergistically with ELF4 to transactivate the IL-3 promoter and with ELF2 to transactivate the mouse BLK promoter. BLK, in turn, is a tyrosine kinase involved in B-lymphocyte development, differentiation, and signaling (Cho et al. 2004).

Network analysis identified two further candidates on SSC13: MYD88 (25.1 Mb) and ZBTB20 (HSA 3, $114 \mathrm{Mb})$. MYD88 is an adapter protein that is involved in the Toll-like receptor and IL-1 receptor signaling pathway in the innate immune response. It is connected to CD14 (see below) via toll-like receptor 1 (TLR1). It increases IL8 transcription and is involved in the IL-18-mediated signaling pathway (Shen et al. 2012).

ZBTB20 is involved in alpha-fetoprotein repression. It is assumed that the protein product is a transcription factor that may be involved in haematopoiesis, oncogenesis, and immune responses (Peterson et al. 2011). Further research is needed for the detection of responsible QTN(s).

Fetuin A was proposed as a potential marker for chronic A. pleuropneumoniae disease by Kahlisch et al. (2009). 
Fetuin A inhibits the production of pro-inflammatory cytokines (IL-1 $\beta$, TNF-alpha, NO) by deactivating macrophages as an opsonin (Dziegielewska et al. 1998; Wang et al. 1998; Kahlisch et al. 2009). Thus, it prevents excessive immune reactions detrimental to the host, an important part in pleuropneumonia (Gottschalk 2012). In the study of Kahlisch et al. (2009), the absence of severe lung lesions in Hampshire line pigs was associated with increased fetuin A levels, when compared to more affected Pietrain and Landrace pigs. Founder animals of the present study came from the same Hampshire and Landrace lines. However, Fetuin A was not differentially expressed in the present study.

Two QTL on SSC2 and SSC12 in the clinical QTL study by Reiner et al. (2014) showed significant combined association of markers Swr345 (SSC2, $114.4 \mathrm{cM} ; 145 \mathrm{Mb}$ ) and S0143 (SSC12, $0 \mathrm{cM}$; $3.8 \mathrm{Mb}$ ) with survival and clinical outcome after challenge with A. pleuropneumoniae. We mapped 10 trans-eQTL (see Table 3) and one ciseQTL, TCN1 $(94 \mathrm{cM} ; 111 \mathrm{Mb})$ to the region of Swr345. Transcobalamin-1 (TCN1) is among the top 30 differentially expressed genes of the study. Its role in inflammatory cell migration and neutrophil metabolism (Johnston et al. 1992) and the significance of neutrophils and macrophages in A. pleuropneumoniae defence (Bossé et al. 2002) prioritizes TCN1 as a candidate gene for A. pleuropneumoniae susceptibility. The causative variant might be located within the TCN1 gene.

Further candidate genes on SSC2 have been deduced by network analysis (LMNB1 [135 Mb], ETF1 [146 Mb], HSPA9 [146 Mb], CD14 [148 Mb], and NR3C1 [151 Mb]) and by transcription factor analysis (ESRRA [6.9 Mb]).

Eukaryotic translation termination factor 1 (ETF1) is a basic regulator of eukaryotic translation termination (IngeVechtomov et al. 2003). NR3C1, a receptor for glucocorticoids, affects inflammatory responses, cellular proliferation, and differentiation in target tissues (Bray and Cotton, 2003). HSPA9 is involved in B-cell development and function (Krysiak et al. 2011). CD14 (cluster of differentiation 14) cooperates with MD-2 and TLR4 to mediate the innate immune response to bacterial lipopolysaccharide (LPS). It acts via MYD88, TIRAP, and TRAF6, leading to NF- $\kappa-B$ activation, cytokine secretion, and the inflammatory response (Tsai et al. 2011). LPS is one of the main virulence factors of A. pleuropneumoniae and a key response of the host defence (Cho et al. 2005). Thus, CD14 seems a prioritized candidate gene in terms of A. pleuropneumoniae susceptibility in this chromosomal region.

LMNB1 has been associated with autosomal dominant leukodystrophy in humans (Dos Santos et al. 2012). ESRRA, the estrogen-related receptor A has been associated with ovarian tumors and osteoporosis (Auld et al. 2012). A possible role of these genes related with pleuropneumonia remains unclear.

Candidate genes on SSC2 deduced by transcription factor analysis are NR1H3 (13.3 Mb), TEAD1 (43.2 Mb), and TCF3 (46.6 Mb). The first gene, NR1H3 (oxysterols receptor LXR-alpha), is involved, among others, in macrophage function and inflammation (Zhu et al. 2012). Its target genes were upregulated in diseased animals. The second gene, TEAD1, is a transcription factor that plays a key role in the Hippo signaling pathway, a pathway involved in organ size control, and tumor suppression by restricting proliferation and promoting apoptosis (Zhang et al. 2012). The third gene, transcription factor 3 (TCF3 [E2A immunoglobulin enhancer binding factors E12/ E47]), is involved in the regulation of immunoglobulin gene expression (de Pooter and Kee 2010). The target genes of both TEAD1 and TCF3 were downregulated in diseased animals.

Candidate genes for the SSC12 QTL emerge from the analysis of transcription factors (STAT3, STAT5A, STAT5B [signal transducer and activator of transcription 3, 5A, 5B; 20.7/20.8 Mb]) and from network analysis (GRB2 [growth factor receptor-bound protein $2 ; 5.8 \mathrm{Mb}$ ] and RPL38 [ribosomal protein L38; $6.9 \mathrm{Mb}$ ]). Members of the STAT gene family are well known to be of specific importance in immune system-related gene regulation (Casanova et al. 2012). GRB2 is involved in macrophage activation, an adapter protein that provides a link between cell surface growth factor receptors and the ras signaling pathway (Tietzel and Mosser 2002), a critical step in $A$. pleuropneumoniae defence (Gottschalk 2012). RPL38 encodes a ribosomal protein that is a component of the $60 \mathrm{~S}$ subunit, thereby being involved in catalyzing protein synthesis (Ota et al. 2004).

The "Seki_inflammatory_response_lps_dn", which represents the response to LPS was enriched in healthy animals, and therefore downregulated in diseased animals. This result is rather unexpected, since LPS acts as an endotoxin and has the potential to elicit a strong immune response in animals. LPS is also one of the main virulence factors of A. pleuropneumoniae and a key factor for the induction of host response (Cho et al. 2005, Chiers et al. 2010). One conceivable reason for this unexpected result could be the involvement of $A$. pleuropneumoniae genes in downregulation of host genes

Three further cis-eQTL mapped to chromosomes with association to clinical QTL (Reiner et al. 2014): GABRA1 (SSC16), LOC100291908 (SSC17), and Ssc.29764.1 (SSC18) (Table 3). GABRA1 (GABA receptor subunit A1) has been described in the context of epilepsia (Lucarini et al. 2007). Loc 100291908 on SSC17 has not yet been functionally characterized. 
Further genes with distinct differential expression have been detected: FCGR2B (Willcocks et al. 2010), C4A (Yang et al. 2007), SOD2 (Wang et al. 2008), CHI3LI (Renkema et al. 1998), IL10, and IL18.

The protein product of SOD2 is involved in the destruction of radicals and is known to play a role in cancer and other diseases. The SOD2 transcript was also differentially expressed in two recent gene expression profiling studies: The first used also the $24 \mathrm{~K}$-microarray like the one used in this study (Drungowski, pers. communication). The second study utilized a microarray with around 5,400 different transcripts (Hedegaard et al. 2007). It is known that SOD2 is regulated by NF- $\kappa-\mathrm{B}$, which was identified as a key regulator of several novel target genes in a study that examined porcine transcriptome changes after infection with salmonella (Wang et al. 2008).

Both cytokines (IL10, IL18) that were differentially expressed play a central role in immunoregulation and inflammation. While IL18 is classified as a pro-inflammatory cytokine, IL10 features anti-inflammatory effects. However, the latter is also involved in B-cell maturation and antibody production. Furthermore, both IL10 and IL18 stimulate certain T-cells. IL10 was also differentially expressed in two recent studies investigating porcine lung infections caused by A. pleuropneumoniae (Drungowski, pers. communication) and the PRRSV (Xiao et al. 2010), respectively. However, no $c i s$-eQTL for these genes have been detected. Thus, differential expression of these genes seems to be rather a result of trans-regulatory genes than a causative mutation within the differentially expressed genes.

The pulmonary surfactant-associated protein D (SP-D) was also depleted in Hampshire pigs of the founder line (Kahlisch et al. 2009). Expression levels of SP-D were significantly linked to 5 trans-eQTL (SSC6, $54 \mathrm{cM}$; SSC10, 74 cM; SSC13, 124 cM; SSC16, 37 cM; SSC 18, 0 cM). Again, the hotspot on SSC13 is involved in differential expression of a gene that has been proposed as a marker for susceptibility to A. pleuropneumoniae in the pig (Kahlisch et al. 2009). The positions on SSC6, SSC16, and SSC18 do further agree with important chromosomal regions involved in clinical susceptibility to A. pleuropneumoniae (Reiner et al. 2014). The decrease in SP-D protein could be a result of polymorphic neutrophil (PMN)-derived secretions of antibacterial enzymes such as serine proteases (Vaandrager and Van Golde 2000; Cooley et al. 2008; Kahlisch et al. 2009).

A gene proposed by Kahlisch et al. (2009) and Benga et al. (2009) as a selection marker for more resistant pigs with regard to A. pleuropneumoniae infection was haptoglobin (HP). Indeed, a QTL in the region of the HP gene was linked to clinical susceptibility (Reiner et al. 2014). Expression QTL for HP could, however, not be detected in the present study. Variation within exons might serve as a possible explanation.
Besides these regulatory candidate genes, gene variants in non regulatory genes might have not been detected, if the efficiency of their protein was affected qualitatively instead of quantitatively (e.g., mutation within exons).

The clinical QTL on SSC2 described by Reiner et al. (2014) in the region of marker Swr345 covers the region of recently described QTL for resistance to Sarcocystis miescheriana (Reiner et al. 2007) and Pseudorabies (Reiner et al. 2002). Potential candidates for this region arise from an Interleukin gene cluster, harboring IL3, IL4, IL, IL9, and IL12. Such QTL regions are of special interest, because they harbour the potential to affect different diseases and pathogen groups.

In our study, we have used several complementary analysis methods to identify and prioritize candidate genes for porcine lung infection such as differential expression analysis, eQTL analysis, and network analysis. Alternative analysis strategies can be applied, for example weighted correlation network analysis (WGCNA; Langfelder and Horvath 2008) which evaluate gene co-expression networks along with phenotype information of the samples under study. To demonstrate this approach, we applied WGCNA to the expression data and identified two clusters of coexpressed genes that correlate significantly with the disease scoring (Supplementary Fig. 2; $p=9.0 \times 10^{-11}$ and $p=2.0 \times 10^{-6}$ ). The genes of the corresponding clusters are listed in Supplementary Table 4.

In conclusion, the combination of positional and functional methods, involving transcriptomics, eQTL-, pathway-, gene set enrichment- and promoter-analysis, has been used to detect and prioritize candidate genes on four chromosomes linked to resistance/susceptibility to A. pleuropneumoniae infection by a clinical QTL study (Reiner et al. 2014). Lung samples from 50 pigs with low and 50 pigs with high susceptibility to A. pleuropneumoniae infection produced 171 differentially expressed genes and $193 \mathrm{eQTL}$ for 105 of DE genes. Gene set enrichment analysis revealed functional annotations from five gene set categories: "Chemical and genetic perturbations", Biocarta pathways, microRNA targets, transcription factor targets, and GO terms. Small sets of prioritized candidate genes were deduced for regions of the major clinical QTL together with a hotspot of A. pleuropneumoniae-defence regulation on SSC13. Further research will be needed to proof or reject their causal role in susceptibility to A. pleuropneumoniae.

\section{References}

Auld KL, Berasi SP, Liu Y, Cain M, Zhang Y, Huard C, Fukayama S, Zhang J, Choe S, Zhong W, Bhat BM, Bhat RA, Brown EL, Martinez RV (2012) Estrogen-related receptor $\alpha$ regulates osteoblast differentiation via $\mathrm{Wnt} / \beta$-catenin signalling. J Mol Endocrinol 48:177-191 
Baltes N, Topitak W, Gerlach GF, Hennig-Pauka I, HoffmannMoujahid M, Ganter M, Rothkotter HJ (2001) Actinobacillus pleuropneumoniae iron transport and urease activity: effects on bacterial virulence and host immune response. Infect Immun 69:472-478

Baltes N, Hennig-Pauka I, Jacobsen I, Gruber AD, Gerlach GF (2003a) Identification of dimethyl sulfoxide reductase in Actinobacillus pleuropneumoniae and its role in infection. Infect Immun 71:6784-6792

Baltes N, Tonpitak W, Hennig-Pauka I, Gruber AD, Gerlach GF (2003b) Actinobacillus pleuropneumoniae serotype 7 siderophore receptor FhuA is not required for virulence. FEMS Microbiol Lett 220:41-48

Beisser D, Klau GW, Dandekar T, Müller T, Dittrich MT (2010) BioNet: an R-package for the functional analysis of biological networks. Bioinformatics 26:1129-1130

Benga L, Hoeltig D, Rehm T, Rothkoetter HJ, Pabst R, ValentinWeigand P, the FUGATO consortium IRAS (2009) Expression levels of immune markers in Actinobacillus pleuropneumoniae infected pigs and their relation to breed and clinical symptoms. BMC Vet Res 5:13

Bishop SC, Axford RFE, Nicholas FW, Owen JB (2010) Breeding for disease resistance in farm animals, 3rd edn. CAB International, Wallingford

Bossé JT, Jansona H, Sheehana BJ, Beddekb AJ, Rycroftb AN, Krolla JS, Langford PR (2002) Actinobacillus pleuropneumoniae: pathobiology and pathogenesis of infection. Microbes Infect 4:225-235

Bray PJ, Cotton RGH (2003) Variations of the human glucocorticoid receptor gene (NR3C1): pathological and in vitro mutations and polymorphisms. Hum Mutat 21:557-568

Casanova JL, Holland SM, Notarangelo LD (2012) Inborn errors of human JAKs and STATs. Immunity 36:515-528

Chiers K, De Waele T, Pasmans F, Ducatelle R, Hasebrouck F (2010) Virulence factors of Actinobacillus pleuropneumoniae involved in colonization, persistence and induction of lesions in its porcine host. Vet Res 41:65

Cho JY, Akbarali Y, Zerbini LF, Gu Z, Boltax J, Wang Y, Oettgen P, Zhang DE, Libermann TA (2004) Isoforms of the Ets transcription factor NERF/ELF-2 physically interact with AML1 and mediate opposing effects on AML1-mediated transcription of the B cell-specific blk gene. J Biol Chem 279:19512-19522

Cho WS, Jung K, Kim J, Ha Y, Chae C (2005) Expression of mRNA encoding Interleukin (IL)-10, IL-12p35 and IL-12p40 in lungs from pigs experimentally infected with Actinobacillus pleuropneumoniae. Vet Res Commun 29:111-122

Churchill GA, Doerge RW (1994) Empirical threshold values for quantitative trait mA. pleuropneumoniaeing. Genetics 138:963971

Cleveland-Nielsen A, Nielsen EO, Ersbol AK (2002) Chronic pleuritis in Danish slaughter pig herds. Prev Vet Med 55:121135

Cooley J, McDonald B, Accurso FJ, Crouch EC, Remold-O’Donnel E (2008) Patterns of neutrophile serine proteases-dependent cleavage of surfactant protein $\mathrm{D}$ in inflammatory lung disease. J Leukoc Biol 83:946-955

Danilowicz E, Martinez-Arias R, Dolf G, Singh M, Probst I, Tümmler B, Höltig D, Waldmann KH, Gerlach GF, Stanke F, Leeb T, the IRAS consortium (2009) Characterization of the porcine transferrin gene (TF) and its association with disease severity following an experimental Actinobacillus pleuropneumoniae infection. Anim Genet 41:424-427

De Bruijn M, Speck NA (2004) Core-binding factors in hematopoiesis and immune function. Oncogene 23:4238-4248

De Pooter RF, Kee BL (2010) E proteins and the regulation of early lymphocyte development. Immunol Rev 238:93-109
Dos Santos MM, Grond-Ginsbach C, Aksay SS, Chen B, Tchatchou S, Wolff NI, Van der Knaap MS, Grau AJ (2012) Adult-onset autosomal dominant leukodystrophy due to LMNB1 gene duplication. J Neurol 259:579-581

Dreyfuß A, Schaller A, Nivollet S, Segers RPAM, Kobisch M, Mieli L, Soerensen V, Hussy D, Miserez R, Zimmermann W, Inderbitzin F, Frey J (2004) Use of recombinant ApxIV in serodiagnosis of Actinobacillus pleuropneumoniae infections, development and prevalidation of the Apx IV Elisa. Vet Microbiol 99:227-238

Dziegielewska KM, Andersen NA, Saunders NR (1998) Modification of macrophage response to lipopolysaccharide by fetuin. Immunol Lett 60:31-35

Ertan P, Berdeli A, Yilmaz O, Gonulal DA, Yuksel H (2010) LY96, UPKIB mutations and TLR4, CD14, MBL polymorphisms in children with urinary tract infection. Indian J Pediatr 78:12291233

Fenwick B, Henry S (1994) Porcine pleuropneumonia. J Am Vet Med Assoc 204:1334-1340

Gottschalk M (2012) Actinobacillosis. In: Zimmermann JJ, Karriker LA, Ramirez A, Schwartz KJ, Stevenson GW (eds) Diseases of swine. Wiley Blackwell, West Sussex, pp 653-669

Gottschalk M, Taylor DJ (2006) Actinobacillus pleuropneumoniae. In: Straw BE, Zimmermann JJ, D'Allaire S, Taylor DJ (eds) Diseases of swine. Blackwell Publishing, Ames, pp 563-576

Green P, Falls K, Crooks S (1990) Documentation for CRI-MAP, version 2.4. Washington University, School of Medicine, St. Louis

Gregersen VR, Sørensen KK, Christensen OF, Busch ME, Vingborg RKK, Velander IH, Lund MS, Bendixen C (2010) Identification of QTL for dorso-caudal chronic pleuritis in 12 crossbred porcine families. Anim Genet 41:509-514

Gutiérrez-Martín CB, García Del Blanco N, Blanco M, Navas J, Rodríguez-Ferri EF (2006) Changes in antimicrobial susceptibility of Actinobacillus pleuropneumoniae isolated from pigs in Spain during the last decade. Vet Microbiol 115:218-222

Haesebrouck F, Chiers K, Van Overbeke I, Ducatelle R (1997) Actinobacillus pleuropneumoniae infections in pigs: the role of virulence factors in pathogenesis and protection. Vet Microbiol 58:49-239

Haley CS, Knott SA, Elsen JM (1994) MA. pleuropneumoniaeing quantitative trait loci in crosses between outbred lines using least squares. Genetics 136:1195-1207

Hannan PC, Bhogal BS, Fish JP (1982) Tylosin tartrate and tiamutilin effects on experimental piglet pneumonia induced with pig lung homogenate containing mycoplasmas, bacteria and viruses. Res Vet Sci 33:76-88

Hedegaard J, Skovgaard K, Mortensen S, Sørensen P, Jensen TK et al (2007) Molecular characterisation of the early response in pigs to experimental infection with Actinobacillus pleuropneumoniae using cDNA microarrays. Acta Vet Scand 49:11

Higgins R, Lariviere S, Mittal KR, Martineau GP, Rousseau P, Cameron J (1985) Evaluation of a killed vaccine against porcine pleuropneumoniae due to Haemophilus pleuropneumoniae. Can Vet J 26:86-89

Hoeltig D, Hennig-Pauka I, Thies K, Rehm T, Beyerbach M, Strutzberg-Minder K, Gerlach GF, Waldmann KH, FUGATOconsortium IRAS (2009) A novel respiratory health score (RHS) supports a role of acute lung damage and pig breed in the course of an Actinobacillus pleuropneumoniae infection. BMC Vet Res 5:14

Inge-Vechtomov S, Zhouravleva G, Philippe M (2003) Eukaryotic release factors (eRFs) history. Biol Cell 95:195-209

Jacobsen MJ, Nielsen JP (1995) Development and evaluation of a selective and indicative medium for isolation of Actinobacillus pleuropneumoniae. Vet Microbiol 47:191-197 
Jacobsen MJ, Nielsen JP, Nielsen R (1996) Comparison of virulence of different Actinobacillus pleuropneumoniae serotypes and biotypes using an aerosol infection model. Vet Microbiol 49:159-168

Jacobsen I, Hennig-Pauka I, Baltes N, Trost M, Gerlach GF (2005) Enzymes involved in anaerobic respiration appear to play a role in Actinobacillus pleuropneumoniae virulence. Infect Immun 73:226-234

Jirawattanapong P, Stockhofe-Zurwieden N, van Leengoed L, Wisselink H, Raymakers R, Cruijsen T, van der Peet-Schwering C, Nielen M, van Nes A (2008) Pleuritis in slaughter pigs: relations between lung lesions and bacteriology in 10 herds with high pleuritis. Res Vet Sci 88:11-15

Johnston J, Yang-Feng T, Berliner N (1992) Genomic structure and mapping of the chromosomal gene for transcobalamin I (TCNI): comparison to human intrinsic factor. Genomics 12:459-464

Kahlisch D, Büttner FFR, Naim HY, Gerlach GF, the IRAS consortium (2009) Glycoprotein analysis of porcine bronchoalveolar lavage fluid reveals potential biomarkers corresponding to resistance to Actinobacillus pleuropneumoniae infection. Vet Res 40:60

Kamburov A, Pentchev K, Galicka H, Wierling C, Lehrach H, Herwig R (2011) ConsensusPathDB: toward a more complete picture of cell biology. Nucleic Acids Res 39(Database issue):D712-D717

Krysiak K, Chen TH, Tibbitts J, Martin MG, Walter MJ (2011) B-cell progenitors are reduced in Hspa9 haploinsufficient mice. Blood 118:1636

Langfelder P, Horvath S (2008) WGCNA: an R package for weighted correlation network analysis. BMC Bioinformatics 9:559

Leiner G, Franz B, Strutzberg K, Gerlach GF (1999) A novel enzymelinked immunosorbent assay using the recombinant Actinobacillus pleuropneumoniae ApxII antigen for diagnosis of pleuropneumonia in pig herds. Clinic Diagn Lab Immunol 6:630-632

Linhart C, Halperin Y, Shamir R (2008) Transcription factor and microRNA motif discovery: the Amadeus platform and a compendium of metazoan target sets. Genome Res 18:1180-1189

Lucarini N, Verrotti A, Napolioni V, Bosco G, Curatolo P (2007) Genetic polymorphisms and idiopathic generalized epilepsies. Pediatric Neurol 37:157-164

Maas A, Meens J, Baltes N, Hennig-Pauka I, Gerlach GF (2006) Development of a DIVA subjunit vaccine against Actinobacillus pleuropneumoniae infection. Vaccine 24:7226-7237

MAQC Consortium (2006) The MicroArray Quality Control (MAQC) project shows inter- and intraplatform reproducibility of gene expression measurements. Nat Biotechnol 24:1151-1161

Noyes EP, Feeney D, Pijoan C (1990) Comparison of the effect of pneumonia detected during lifetime with pneumonia detected at slaughter on growth in swine. J Am Vet Med Assoc 197:10251029

Ota T, Suzuki Y, Nishikawa T, Otsuki T, Sugiyama T, Irie R, Wakamatsu A, Hayashi K, Sato H, Nagai K, Kimura K, Makita H, Sekine M, Obayashi M, Nishi T, Shibahara T, Tanaka T, Ishii S, Sugano S (2004) Complete sequencing and characterization of 21,243 full-length human cDNAs. Nat Genet 36:40-45

Peterson ML, Ma C, Spear BT (2011) Zhx2 and Zbtb20: novel regulators of postnatal alpha-fetoprotein repression and their potential role in gene reactivation during liver cancer. Sem Cancer Biol 21:21-27

Reiner G (2009) Investigations on genetic disease resistance in swine: a contribution to the reduction of pain, suffering and damage in farm animals. Appl Anim Behav Sci 118:217-221

Reiner G, Melchinger E, Kramarova M, Pfaff E, Büttner M, Saalmüller A, Geldermann H (2002) Detection of quantitative trait loci for resistance/susceptibility to the Pseudorabies Virus in swine. J Gen Virol 83:167-172
Reiner G, Willems H, Berge T, Fischer R, Köhler F, Hepp S, Hertrampf B, Kliemt D, Daugschies A, Zahner H, Geldermann $\mathrm{H}$, Mackenstedt U (2007) Mapping of quantitative trait loci for resistance/susceptibility to Sarcocystis miescheriana in swine. Genomics 89:638-646

Reiner G, Bertsch N, Hoeltig D, Selke M, Willems H, Gerlach GF, Tuemmler B, Probst I, Herwig R, Drungowski M, Waldmann KH (2014) Identification of QTL affecting resistance/susceptibility to acute Actinobacillus pleuropneumoniae infection in swine. Mamm Genome 25:180-191

Renkema GH, Boot RG, Au FL, Donker-Koopman WE, Strijland A et al (1998) Chitotriosidase, a chitinase, and the 39-kDa human cartilage glycoprotein, a chitin-binding lectin, are homologues of family 18 glycosyl hydrolases secreted by human macrophages. Eur J Biochem 251:504-509

Seaton G, Hernandez J, Grunchec JA, White I, Allen J, De Koning DJ, Wei W, Berry D, Haley C, Knott S (2006) GridQTL: A Grid Portal for QTL MA. pleuropneumoniaeing of compute intensive datasets. In: Proceedings of the 8 th world congress on genetics A. pleuropneumoniaelied to livestock production, August 13-18, 2006, Belo Horizonte

Shao M, Wang Y, Wang C, Guo Y, Peng Y, Liu J, Li G, Liu H, Liu S (2010) Evaluation of multicomponent recombinant vaccines against Actinobacillus pleuropneumoniae in mice. Acta Vet Scand 52:52

Shen Z, Seppänen H, Vainionpää S, Ye Y, Wang S, Mustonen H, Puolakkainen P (2012) IL10, IL11, IL18 are differently expressed in CD14 + TAMs and play different role in regulating the invasion of gastric cancer cells under hypoxia. Cytokine 59:352-357

Sjölund S, Wallgren P (2010) Field experience with two different vaccination strategies aiming to control infections with. Actinobacillus pleuropneumoniae in a fattening pig herd. Acta Vet Scand 52:23

Subramanian A, Tamayo P, Mootha VK, Mukherjee S, Ebert BL, Gillette MA, Paulovich A, Pomeroy SL, Golub TR, Lander ES, Mesirov JP (2005) Gene set enrichment analysis: a knowledgebased approach for interpreting genome-wide expression profiles. Proc Natl Acad Sci 102:15545-15550

Tietzel I, Mosser DM (2002) The modulation of macrophage activation by tyrosine phosphorylation. Front Biosci 7:d1494d1502

Tonpitak W, Baltes N, Hennig-Pauka I, Gerlach GF (2002) Construction of an Actinobacillus pleuropneumoniae serotype 2 prototype live negative-marker vaccine. Infect Immun 70:7120-7125

Tsai TH, Chen SF, Huang TY, Tzeng CF, Chiang AS, Kou YR, Lee TS, Shyue SK (2011) Impaired CD14 and CD36 expression, bacterial clearance, and Toll-like receptor 4YMYD88 signaling in Caveolin-1Y deleted macrophages and mice. Shock 35:92-99

Tumamao JQ, Bowles RE, van den Bosch H, Klaasen HL, Fenwick BW, Storie GJ, Blackall PJ (2004) Comparison of the efficacy of a subunit and a live streptomycin-dependent porcine pleuropneumonia vaccine. Aust Vet J 82:370-374

Vaandrager AB, Van Golde LM (2000) Lung surfactant proteins A and $\mathrm{D}$ in innate immune defense. Biol Neonate 77(Suppl 1):9-13

Van Oirschot JT (1994) Vaccination in food animal populations. Vaccine 12:415-418

Wang H, Zhang M, Bianchi M, Sherry B, Sama A, Tracey KJ (1998) Fetuin (alpha2-HS-glycoprotein) opsonises cationic macrophage deactivating molecules. Proc Natl Acad Sci USA 95:1442914434

Wang Y, Ren J, Lan L, Yan X, Huang X, Peng Q, Tang H, Zhang B, Ji H, Huang L (2007) Characterization of polymorphisms of transferrin receptor and their association with susceptibility to ETEC F4ab/ac in pigs. J Anim Breed Genet 124:225-229 
Wang Y, Couture OP, Qu L, Uthe JJ, Bearson SM et al (2008) Analysis of porcine transcriptional response to Salmonella enterica serovar Choleraesuis suggests novel targets of NFkap$\mathrm{paB}$ are activated in the mesenteric lymph node. BMC Genomics 20:1-20

Wanschers B, van de Vorstenbosch R, Wijers M, Wieringa B, King SM, Fransen J (2008) Rab6 family proteins interact with the dynein light chain protein DYNLRB1. Cell Motil Cytoskeleton 65:183-196

Wessel J, Zapala MA, Schork NJ (2007) Accommodating pathway information in expression quantitative trait locus analysis. Genomics 90:132-142

White DG, Zhao S, Simjee S, Wagner DD, McDermott PF (2002) Antimicrobial resistance of food born pathogens. Microbes Infect 4:405-412

Willcocks LC, Carr EJ, Niederer HA, Rayner TF, Williams TN et al (2010) A defunctioning polymorphism in FCGR2B is associated with protection against malaria but susceptibility to systemic lupus erythematosus. Proc Natl Acad Sci USA 107:7881-7885

Wu C, Delano DL, Mitro N, Su SV, Janes J, McClurg P, Batalov S, Welch GL, Zhang J, Orth AP, Walker JR, Glynne RJ, Cooke MP, Takahashi JS, Shimomura K, Kohsake A, Bass J, Saez E, Wiltshire T, Su AI (2008) Gene enrichment in eQTL data identifies novel annotations and pathway regulators. PLoS Genet 4:e1000070
Xiao S, Jia J, Mo D, Wang Q, Qin L et al (2010) Understanding PRRSV infection in porcine lung based on genome-wide transcriptome response identified by deep sequencing. PLoS One 5:e11377

Yang Y, Chung EK, Wu YL, Savelli SL, Nagaraja HN et al (2007) Gene copy-number variation and associated polymorphisms of complement component $\mathrm{C} 4$ in human systemic lupus erythematosus (SLE): low copy number is a risk factor for and high copy number is a protective factor against SLE susceptibility in European Americans. Am J Hum Genet 80:1037-1054

Yvert G, Brem RB, Whittle J, Akey JM, Foss E et al (2003) Transacting regulatory variation in Saccharomyces cerevisiae and the role of transcription factors. Nat Genet 35:57

Zhang X, Grusche FA, Harvey KF (2012) Control of tissue growth and cell transformation by the Salvador/Warts/Hippo pathway. PLoS One 7:e31994

Zhu R, Ou Z, Ruan X, Gong J (2012) Role of liver X receptors in cholesterol efflux and inflammatory signaling. Mol Med Rep 5:895-900

Zutic M, Ruzica A, Milic N (2008) Isolation and identification of Actinobacillus pleuropneumoniae in pig's lungs at farms and their sensitivity to antibiotics. Acta Vet 58:499-507 